Cochrane Database of Systematic Reviews

\title{
Acupuncture for cancer pain in adults (Review)
}

Paley CA, Johnson MI, Tashani OA, Bagnall AM

Paley CA, Johnson MI, Tashani OA, Bagnall A-M.

Acupuncture for cancer pain in adults.

Cochrane Database of Systematic Reviews 2015, Issue 10. Art. No.: CD007753.

DOI: 10.1002/14651858.CD007753.pub3.

www.cochranelibrary.com 
HEADER 1

ABSTRACT

PLAIN LANGUAGE SUMMARY

BACKGROUND

OBJECTIVES

METHODS

Figure 1.

RESULTS

Figure 2.

Figure 3.

DISCUSSION

AUTHORS' CONCLUSIONS

ACKNOWLEDGEMENTS

REFERENCES

CHARACTERISTICS OF STUDIES

ADDITIONAL TABLES

APPENDICES

WHAT'S NEW

HISTORY

CONTRIBUTIONS OF AUTHORS

DECLARATIONS OF INTEREST

SOURCES OF SUPPORT

DIFFERENCES BETWEEN PROTOCOL AND REVIEW

NOTES

INDEX TERMS

\section{TABLE OF CONTENTS}

INDEX TERMS 
[Intervention Review]

\title{
Acupuncture for cancer pain in adults
}

\author{
Carole A Paley $^{1}$, Mark I Johnson², Osama A Tashani², Anne-Marie Bagnall2
}

${ }_{1}^{1}$ Research \& Development Department, Airedale NHS Foundation Trust, Keighley, UK. 2Faculty of Health and Social Sciences, Leeds Beckett University, Leeds, UK

Contact address: Carole A Paley, carolepaley2@btinternet.com.

Editorial group: Cochrane Pain, Palliative and Supportive Care Group.

Publication status and date: Stable (no update expected for reasons given in 'What's new'), published in Issue 3, 2021.

Citation: Paley CA, Johnson MI, Tashani OA, Bagnall A-M. Acupuncture for cancer pain in adults. Cochrane Database of Systematic Reviews 2015, Issue 10. Art. No.: CD007753. DOI: 10.1002/14651858.CD007753.pub3.

Copyright @ 2015 The Cochrane Collaboration. Published by John Wiley \& Sons, Ltd.

\section{A B S T R A C T}

\section{Background}

Forty per cent of individuals with early or intermediate stage cancer and $90 \%$ with advanced cancer have moderate to severe pain and up to $70 \%$ of patients with cancer pain do not receive adequate pain relief. It has been claimed that acupuncture has a role in management of cancer pain and guidelines exist for treatment of cancer pain with acupuncture. This is an updated version of a Cochrane Review published in Issue 1, 2011, on acupuncture for cancer pain in adults.

\section{Objectives}

To evaluate efficacy of acupuncture for relief of cancer-related pain in adults.

\section{Search methods}

For this update CENTRAL, MEDLINE, EMBASE, PsycINFO, AMED, and SPORTDiscus were searched up to July 2015 including non-English language papers.

\section{Selection criteria}

Randomised controlled trials (RCTs) that evaluated any type of invasive acupuncture for pain directly related to cancer in adults aged 18 years or over.

\section{Data collection and analysis}

We planned to pool data to provide an overall measure of effect and to calculate the number needed to treat to benefit, but this was not possible due to heterogeneity. Two review authors (CP, OT) independently extracted data adding it to data extraction sheets. Data sheets were compared and discussed with a third review author (MJ) who acted as arbiter. Data analysis was conducted by CP, OT and MJ.

\section{Main results}

We included five RCTs (285 participants). Three studies were included in the original review and two more in the update. The authors of the included studies reported benefits of acupuncture in managing pancreatic cancer pain; no difference between real and sham electroacupuncture for pain associated with ovarian cancer; benefits of acupuncture over conventional medication for late stage unspecified cancer; benefits for auricular (ear) acupuncture over placebo for chronic neuropathic pain related to cancer; and no differences between conventional analgesia and acupuncture within the first 10 days of treatment for stomach carcinoma. All studies had a high risk of bias from inadequate sample size and a low risk of bias associated with random sequence generation. Only three studies had low risk of bias associated with incomplete outcome data, while two studies had low risk of bias associated with allocation concealment and one study had low risk of bias associated with inadequate blinding. The heterogeneity of methodologies, cancer populations and techniques used in the included studies precluded pooling of data and therefore meta-analysis was not carried out. A subgroup analysis on acupuncture 
for cancer-induced bone pain was not conducted because none of the studies made any reference to bone pain. Studies either reported that there were no adverse events as a result of treatment, or did not report adverse events at all.

\section{Authors' conclusions}

There is insufficient evidence to judge whether acupuncture is effective in treating cancer pain in adults.

\section{PLAIN LANGUAGE SUMMARY}

\section{Acupuncture for cancer-related pain in adults}

\section{Backgound}

Up to $70 \%$ of patients with cancer pain do not receive adequate pain relief and this reduces their quality of life. It has been claimed that acupuncture has a role in the management of cancer pain and guidelines exist for treatment of cancer pain with acupuncture.

\section{Purpose of this research}

The authors of this Cochrane Review decided to evaluate the evidence for whether acupuncture is effective in reducing pain directly associated with the development of cancer.

\section{The search for evidence}

We searched a wide range of electronic medical databases up to July 2015 for relevant studies. We included studies written in any language that included adults and compared treatment with acupuncture for cancer pain against no treatment, or usual treatment, or sham acupuncture, or other treatments. Since we were only interested in robust research, we restricted our search to randomised controlled trials (in which participants are randomly allocated to the methods being tested).

\section{What we found}

We found five studies (with a total of 285 participants) that compared acupuncture against either sham acupuncture or pain-killing medicines. All five identified studies had small sample sizes, which reduces the quality of their evidence.

One pilot study was well designed, but was too small to identify any differences in pain in women with ovarian cancer after electroacupuncture or a sham treatment. One study found that auricular (ear) acupuncture reduced cancer pain when compared with sham auricular acupuncture that was given at non-acupuncture points. However, the people in the sham acupuncture group could have been aware that they were not in the real acupuncture group and this could have affected the level of pain they reported. Another study found a difference between an electroacupuncture group and sham group in people with pancreatic cancer but again, there was no reported attempt to conceal which group people were in. One study found that acupuncture was as effective as pain-killing medication, and one study found that acupuncture was more effective than medication, but both studies were poorly designed and the study reports lacked detail.

\section{Conclusions}

None of the studies described in this review were big enough to produce reliable results. None of the studies reported any harm to the participants. We conclude that there is insufficient evidence to judge whether acupuncture is effective in relieving cancer pain in adults. Larger, well-designed studies are needed to provide evidence in this area. 


\section{B A C K G R O U N D}

This is an updated version of the original Cochrane Review, 'Acupuncture for cancer pain in adults', published in the Cochrane Library Issue 1, 2011

\section{Description of the condition}

Cancer-related pain represents a major challenge in health care. Forty per cent of individuals with early or intermediate stage cancer and $90 \%$ of individuals with advanced cancer have moderate to severe pain (Laird 2008; Payne 1998). Pain in cancer patients may be due to pre-existing pathologies, progression of the disease, tumour growth, bone metastases (cancer-induced bone pain (CIBP)) or the treatment of cancer itself (Strong 2002; Twycross 2008; Urch 2008). Bone pain due to metastatic cancer is often particularly severe, unremitting and poorly controlled with patients often having to take high doses of analgesic drugs with undesirable side-effects (Gralow 2007). Up to $70 \%$ of patients with cancer-related pain do not receive adequate pain relief and this affects physical and psychological well-being, and leads to a lower quality of life for the patient (Keskinbora 2007; Vallerand 2007; van den Beuken-van Everdingen 2007a; van den Beuken-van Everdingen 2007b).

\section{Description of the intervention}

Acupuncture is a treatment intervention delivered by practitioners aligned to different philosophical paradigms (MacPherson 2007). Acupuncture is used throughout the world to manage nonmalignant acute and chronic pain. It is claimed that acupuncture has a role in the management of cancer pain (Alimi 2003; Dillon 1999; Filshie 2004), and guidelines exist for the treatment of cancer pain with acupuncture (Filshie 2006). Anecdotal evidence suggests that it is routinely used in clinical practice by physiotherapists for a variety of pain states (Hopwood 2004), and increasingly by the medical profession for pain relief in general (MacPherson 2007). Filshie 1990 described the use of acupuncture for malignant pain on 193 cancer patients over a five-year period and reported that 56\% of patients had a 'worthwhile' improvement for seven days or more and $22 \%$ had an improvement for a 'limited duration'; a further $22 \%$ obtained no benefit at all.

There continues to be a debate about the efficacy of acupuncture (Ernst 2006). Some systematic reviews and meta-analyses report that acupuncture is superior to placebo or sham acupuncture for osteoarthritis of the knee (Bjordal 2007; White 2007), peripheral joint osteoarthritis (Kwon 2006), post-operative pain (Sun 2008), neck and shoulder pain (He 2004; Trinh 2006), and chronic low back pain (Furlan 2005; Manheimer 2005). However, other review authors have found limited efficacy for osteoarthritis of the knee (Manheimer 2007), tension-type headache (Davis 2008), inconclusive evidence for shoulder pain (Green 2005), and chronic pain in general (Ezzo 2000).

A systematic review of systematic reviews of acupuncture published between 1996 to 2005, claimed to apply more rigorous inclusion criteria than previous reviews and concluded that there was no robust evidence that acupuncture is superior to a sham acupuncture control (Derry 2006). Trials that compared acupuncture with sham acupuncture and with patients on a waiting list tended to show benefits for both acupuncture and sham over the waiting list group. Sham acupuncture can either be a nonpenetrative sham (i.e. it has the appearance of real acupuncture, but the needle is blunt and does not penetrate the skin) or penetrative sham (i.e. where the needle penetrates the skin, but is used on non-acupuncture points). It has been suggested that the dosage of acupuncture required for a beneficial effect is a minimum of six treatments using at least four points at a frequency of at least once a week, although the evidence supporting these recommendations has not been widely researched (Ezzo 2000; White 2007). White 2007 also suggests that the needle sensation, 'de qi', or in electro-acupuncture a strong sensation of paraesthesiae ('pins and needles') must be achieved for optimum benefit.

When the original review was conducted only one other systematic review of acupuncture for cancer pain had been conducted (Lee 2005), but this did not use a Cochrane protocol. Seven studies met the eligibility criteria: three were randomised controlled trials (RCTs) and four were uncontrolled studies. From the eligible randomised controlled trials only one high-quality, small RCT was identified (Alimi 2003), and the investigators concluded that auricular (ear) acupuncture provided statistically significant pain relief when compared with placebo acupuncture. It was not possible to meta-analyse the results of the review due to heterogeneity in pain states, patient populations and acupuncture protocols in the identified studies. Four studies used body acupuncture, two used auricular acupuncture and one used electro-acupuncture (where an electric current is transmitted via the needles). The control groups were either patients receiving conventional therapies or placebo/sham acupuncture. The review authors concluded that there was insufficient good quality evidence to determine the effectiveness of acupuncture in relieving cancer pain.

Since our original Cochrane review there have been new systematic reviews of complementary therapies including acupuncture for cancer pain. Bardia 2006 was a systematic review of the effectiveness of complementary and alternative medicine therapies for cancer related pain but was unable to evaluate the efficacy of acupuncture because of insufficient good quality evidence. Bao 2014 conducted an overview of systematic reviews of complementary and alternative medicine for adult cancer pain in which 27 systematic reviews were identified Another four reviews have assessed the effect of acupuncture on cancer pain in addition to our original Cochrane Review (Choi 2012; Garcia 2013; Lee 2005; Lian 2014). Choi 2012 found tentative evidence that acupuncture plus drug therapy was better than drug therapy alone in managing cancer pain. Lian 2014 concluded that acupuncture had 'promising' effectiveness for treating cancer pain. Garcia 2013 and Lee 2005 concluded that there was insufficient evidence to support the use of acupuncture for cancer-related pain, and that efficacy was undetermined, largely due to a high risk of bias among studies. The Towler 2013 overview of systematic reviews included 17 reviews, but found that there was too much variation in the quality and approach within trials to make meaningful conclusions about effectiveness, though it did make recommendations about an adequate intervention, suitable outcome measures and reporting standards for future trials.

Bone metastases are common in advanced cancers, particularly in patients with multiple myeloma, breast, prostate or lung cancer (Brainin-Mattos 2006; Lipton 2004). The incidence of bone involvement has been said to exceed $90 \%$ in metastatic prostate and breast cancers (Rosier 1998). Bone pain due to metastatic cancer is severe, unremitting and poorly controlled (Gralow 
2007; Ripamonti 2000). Mainstay treatments are opiates and bisphosphonates, although these can have severe adverse effects (Petrut 2008). Nowadays, the survival rate of many patients after diagnosis of bone metastases is relatively long; five-year survival rates have been quoted at $64 \%$ for metastatic breast disease and $46 \%$ for metastatic prostate cancers (Coleman 2001). In view of this it is important to control pain and preserve function to enable these patients to enjoy as high a quality of life as possible (Qaseem 2008). Filshie 1990 claims that acupuncture is useful in 'selected' patients with CIBP, where pain is difficult to control adequately and pharmacological input is very high, and results in unpleasant sideeffects. To date, no systematic reviews on acupuncture for CIBP have been conducted, and therefore the efficacy of acupuncture as a treatment for CIBP is unknown.

\section{Why it is important to do this review}

To date, the only Cochrane Review on acupuncture for cancerrelated pain is our original review from 2011. At the time of the original review only one systematic review of acupuncture for cancer pain had been conducted (Lee 2005). Since the original Cochrane Review in 2011 there have been additional systematic reviews that have been summarised separately by two authors (Bao 2014; Towler 2013). These summaries concluded that there were too few RCTs of sufficiently high quality to determine whether acupuncture was effective in relieving cancer pain. Other systematic reviews have been conducted, but they did not specifically focus on pain.

None of the systematic reviews identified in this review have analysed CIBP as a subgroup, even though this type of pain is extremely severe and difficult to control. The high incidence of CIBP merits a subgroup analysis, although preliminary searches have not revealed any controlled trials. It is necessary to establish whether any studies exist, the quality of the research and any important findings. Within the review as a whole and in the subgroup analysis on CIBP, we will not exclude studies with heterogeneous cancer populations, and we will identify and discuss heterogeneous studies as part of the review.

\section{O B JECTIVES}

To evaluate the efficacy of acupuncture for the relief of cancerrelated pain in adults.

\section{METHODS}

\section{Criteria for considering studies for this review}

\section{Types of studies}

We included randomised controlled trials (RCTs) of either crossover or parallel group design that evaluated any type of invasive acupuncture for pain directly linked to the development of cancer in adults, from inception of each database onwards. These included studies that did not blind the therapist, as blinding an acupuncturist to the treatment is problematical. We excluded studies if they were non-randomised trials, case reports, abstracts and letters (unless they provided additional information from published RCTs).

\section{Types of participants}

We included adult participants of 18 years or older with cancerrelated pain. We defined cancer-related pain as pain directly linked to the development of cancer and not due to pre-existing pathologies or related to treatments; for example, chemotherapyinduced neuropathic pain (Cata 2006), or procedures such as surgery. We intended to review CIBP as our subgroup analysis, if the data allowed.

\section{Types of interventions}

We included studies that evaluated any type of invasive acupuncture. This included studies that used manual acupuncture, electro-acupuncture and auricular (ear) acupuncture. We included both Western style and traditional Chinese acupuncture. Westernstyle acupuncture is characterised by its scientific approach, using a physiologically-based rationale for the treatment and explanation of its effects, whereas traditional Chinese acupuncture is based on the ancient principles of Chinese medicine. We also included studies that used different forms of needle stimulation (such as electroacupuncture) and different needling techniques, but we excluded studies that used comparisons of non-invasive techniques such as laser acupuncture or acupressure.

Since pain outcomes may be compromised in studies that allow free access to analgesic medication, we planned to include such studies in the review and analyse them as a sub-group for differences in analgesic consumption between groups.

We also intended to perform a subgroup analysis on adequacy of acupuncture based on the following criteria (White 2007):

- number of needles: at least four acupuncture points;

- needling technique: at least 20 minutes per session;

- needle sensation: reported as 'de qi' or needle sensation for manual acupuncture or a 'strong sensation' for electroacupuncture;

- number of treatments: at least six treatments with at least one per week.

The intervention to be compared with acupuncture would include any of the following:

- no treatment;

- treatment as usual;

- non-penetrative sham (i.e. non-invasive treatment);

- penetrative sham (i.e. invasive treatment at non-acupuncture points);

- other active interventions.

\section{Types of outcome measures}

\section{Primary outcomes}

The primary outcome measure was patient-reported pain intensity using validated scales (e.g. visual analogue scales (VAS), numerical rating scales) or verbal reporting.

\section{Secondary outcomes}

Secondary outcome measures included any of the following:

- pain relief as measured by validated pain scales (e.g. VAS);

- patient satisfaction;

- quality of life;

- analgesic consumption and changes in concurrent treatments; 
- hospital attendance/admission (including Hospice admission);

- adverse events (major or minor).

\section{Search methods for identification of studies}

\section{Electronic searches}

We searched the following databases:

- the Cochrane Central Register of Controlled Trials (CENTRAL) via the Cochrane register of Studies Online (CRSO), searched on 4 August 2015;

- MEDLINE and Medline in Process (OVID) 1946 to 31 July 2015;

- EMBASE (OVID) 1974 to 31 July 2015;

- PsycINFO (OVID) 1806 to 31 July 2015;

- AMED (OVID) 1985 to 31 July 2015;

- SPORTDiscus (EBSCO) to July 2015.

We developed detailed search strategies for each electronic database that was searched in order to identify studies suitable for inclusion in the review. These were based on the search strategy developed for MEDLINE, but were revised according to the database being used (see Appendix 1; Appendix 2).
The MEDLINE search was carried out using the Cochrane Highly Sensitive Search Strategy (CHSSS) for identifying randomised trials in MEDLINE via Ovid filter, as published in Chapter 6.4.11.1 of the Cochrane Handbook for Systematic Reviews of Interventions (Higgins 2011).

The search strategy attempted to identify all relevant studies irrespective of language of publication. We assessed non-English papers for relevance and made decisions on translation on a case-by-case basis, as suggested in the Cochrane Handbook for Systematic Reviews of Interventions (Higgins 2011).

\section{Searching other resources}

We also reviewed reference lists of eligible studies and previous systematic reviews to identify further eligible studies. We did not search Chinese and Korean databases directly and acknowledge that further relevant literature might exist. However, other systematic reviews which we searched as part of this review did include Chinese and Korean database searches (Choi 2012; Lee 2005).

\section{Data collection and analysis}

The study selection process is shown in Figure 1. 


\section{Figure 1. Study flow diagram}

\begin{tabular}{|l|} 
Number (\#) of studies \\
included in previous version \\
of review \\
3
\end{tabular}

\# of records

identified

through

database

searching

568
\# of additional

records

identified

through other

sources

0

\# of records after

duplicates removed

387

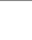

\# of studies

included in

narrative

synthesis

5

\# of full records

screened

following title

and abstract

screening

20
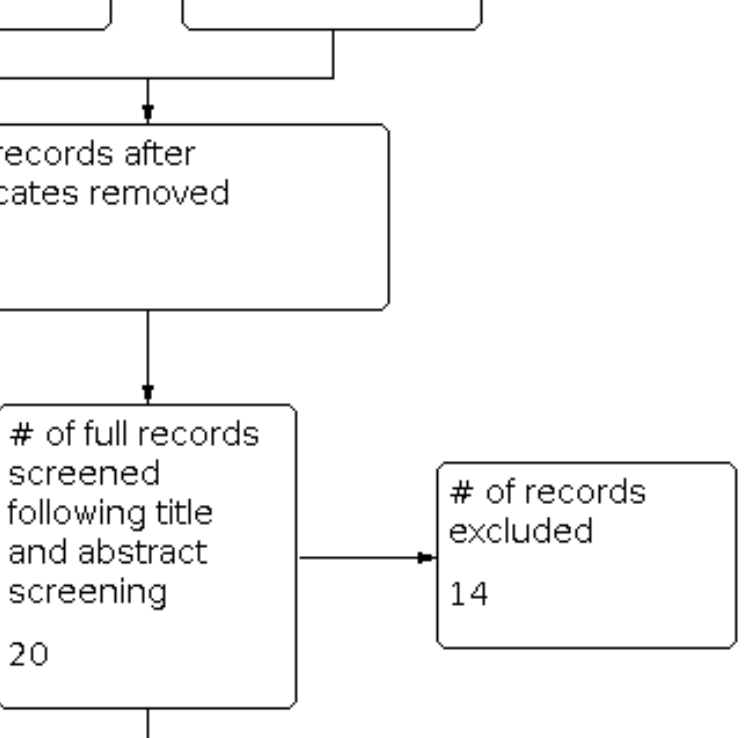
Figure 1. (Continued)

\begin{tabular}{|l|} 
included in \\
quantitative \\
synthesis \\
(meta-analysis) \\
0
\end{tabular}

\section{Selection of studies}

Two review authors (CP and OT), with a third review author (MJ) acting as arbiter, independently selected the studies to be considered in the review following the literature searches described in the previous section.

\section{Data extraction and management}

We conducted data extraction up to and including July 2015. We completed a search log that showed the databases searched and the dates of searches. We completed a data extraction sheet for every study included in the review. We recorded information on details of authors, participants, study design, characteristics of intervention (acupuncture style, type of needle, number of needles, needling technique, needle sensation and number of treatments) and comparator, any adverse effects and baseline/end of study outcomes.

\section{Assessment of risk of bias in included studies}

Methodological quality was independently assessed using the Cochrane tool for assessing risk of bias in RCTs. Two review authors completed the data extraction and scored each study (CP and $\mathrm{OT}$ ), with a third review author (MJ) acting as arbiter where differences occurred between CP and OT. We summarised risk of bias and settled differences in author interpretation of data through discussion.

\section{Measures of treatment effect}

We planned to pool data from the outcomes of each study to provide an overall measure of the effect of acupuncture on cancerrelated pain, except where different cut-off points were used (see below). For continuous data, we intended that results would be presented as weighted mean differences (WMD). However, if different pain scales were used in the acupuncture studies we planned to present this data using standardised mean differences (SMD) where appropriate. Where dichotomous data existed, we would use risk ratio (RR).

\section{Unit of analysis issues}

The problem of dividing categorical data into dichotomous outcomes provides a potential source of bias, as study authors might use different cut-off points for the data in each group. Wes planned that we would not pool outcomes from data with different cut-off points, or data from clinically heterogeneous studies, as described above. We would combine data for all treatment periods.

\section{Dealing with missing data}

We planned to describe studies with missing data in the text and to illustrate them using tables as appropriate. To avoid bias arising from missing data, we would perform an intention-to-treat analysis (ITT) where data were continuous, using the last observation on each participant carried forward until the study endpoint. Where missing dichotomous data were identified we planned to assign these positive and negative outcomes in equal proportions. If the number of missing values was significant, we decided that it might be necessary to perform a sensitivity analysis to estimate the effect of the ITT analysis on the overall outcome. We planned to do this by assuming a positive outcome for all missing data, followed by a negative outcome for the missing data and assuming that the outcome would lie near the midpoint between the two values.

We decided not to exclude studies with a high attrition rate $(50 \%$ or more) from the review because it was expected that there would be very few studies that met the inclusion criteria.

\section{Assessment of heterogeneity}

We planned to use a $\mathrm{Chi}^{2}$ test to estimate heterogeneity of both the SMD and RR. Further analysis could be performed using the $I^{2}$ test. If possible, we would also construct a forest plot for analysis. Where heterogeneity was statistically significant, we planned to use a random-effects model to interpret the results. If heterogeneity was not statistically significant, we would use a fixed-effect model.

Potential sources of heterogeneity exist in the outcomes used (e.g. differences in methods of reporting pain), population (differences in cancer site and nature, or cause of pain, age, gender, etc.), comparators used (e.g. sham/placebo, waiting list) and study design. We planned that we would analyse all studies we identified for the review to identify possible sources of heterogeneity and discuss this in the text of the review.

\section{Assessment of reporting biases}

We decided that, if the review authors did not find a large number of studies, we would not assess publication or inclusion bias. However, if enough studies were available, and a meaningful assessment of publication bias could be carried out, we planned to construct a funnel plot.

\section{Data synthesis}

If the data could be combined into a meta-analysis, we would include categorical data only where it could be divided into dichotomous outcomes. If the data could not be combined in a meta-analysis, we decided to summarise them in the text and group them by outcome as appropriate. We would enter all data into Review Manager (RevMan) 5 analysis software (RevMan 2014).

\section{Subgroup analysis and investigation of heterogeneity}

Where the data allowed, we planned to separate the outcome analyses and perform a subgroup analysis on outcomes of studies that used acupuncture specifically for CIBP. 


\section{Sensitivity analysis}

We planned to explore other sources of heterogeneity using sensitivity analysis to determine the effects of the method of acupuncture treatment, overall methodological quality and use of ITT analysis. If there were any studies with high attrition rates (over $50 \%$ ), we would remove them from the meta-analysis to determine whether the results would be significantly different without them.

\section{RES U L T S}

\section{Description of studies}

See the 'Characteristics of included studies' and 'Characteristics of excluded studies' tables.

\section{Results of the search}

For inclusion in the review, studies had to meet all of the three main eligibility criteria which were:

- investigate acupuncture for cancer pain;

- contain clinical data;

- be randomised controlled trials (RCTs).

We excluded case reports, abstracts and letters. Where we identified abstracts for RCTs we sought the full reports and included them if available. A flowchart showing the selection process is shown in Figure 1. In total, for this update we identified 568 new references, from which it was possible to exclude 181 duplicates, leaving 387 studies to be considered for the update. We excluded a further 339 studies from the titles alone. We obtained abstracts for the remaining 48 studies and excluded a further 28 because they did not investigate acupuncture, or cancer pain, or combined acupuncture with another intervention, or were systematic reviews, or not RCTs. Three studies could not be excluded at this stage because they needed to be translated from French (Nguyen 2005), German (Meng 2002), and Chinese (Chen 2008). Once translated, we excluded two of these studies as they did not meet the inclusion criteria (Meng 2002; Nguyen 2005). For the 2015 update, we obtained full study reports for 20 studies and excluded a further 14 because further examination revealed that they were postoperative studies, or did not have pain as a main outcome measure, or were duplicates, or translation revealed that they were not RCTs. Six full-text articles were assessed for eligibility in the update and four were finally excluded, with reasons specified in Characteristics of excluded studies. A total of 17 excluded studies are listed in Characteristics of excluded studies from both versions of this review. We included five studies in the final updated review (Alimi 2003; Chen 2008; Chen 2013; Dang 1998; Lu 2012), and one study, Dang 1997, was added as a secondary reference to Dang 1998. We identified three for the original review and two additional ones for the 2015 update (Chen 2013; Lu 2012).

\section{Included studies}

Five studies (285 participants) met the criteria for inclusion (see Characteristics of included studies). We identified an additional study, Dang 1997, but because it contained data duplicated in a later report we included it as a secondary reference for an already included study, Dang 1998.

The Alimi 2003 study was included in the original review. This study randomly assigned 90 participants with chronic peripheral or central neuropathic pain related to cancer to one of the three groups:

- auricular acupuncture using semi-permanent needles;

- auricular acupuncture using semi-permanent needles administered at non-acupuncture (placebo) points;

- non-invasive auricular 'seeds' administered at non-acupuncture (placebo) points.

Mean pain intensity on visual analogue scale (VAS) was similar in each group at baseline ( 57 to $58 \mathrm{~mm}$ ). Each group received two courses of treatment with needles or seeds left in situ and were asked not to modify their analgesic medication during the course of the study.The duration of each course was determined by the time it took the needles to fall out or for the ear seeds to become unstuck and fall off. Pain scores were recorded at one month (referred to as D30 in the report) and two months (D60 in the report). Measures of electrodermal response at points on the ear were also taken at the same intervals. No adverse events were reported by participants or their doctors. The main outcome measure was pain at two months, with secondary outcomes being pain at one month and electrodermal response at one and two months.

The reported results showed a significant decrease in pain intensity of $36 \%$ ( $58 \mathrm{~mm}$ to $37 \mathrm{~mm}$ on VAS) from baseline at two months in the acupuncture group and no change in the group having acupuncture at placebo points (58 $\mathrm{mm}$ to $55 \mathrm{~mm}$ on VAS). The difference-inchange between the acupuncture and placebo acupuncture groups was statistically significant $(P$ value $<0.0001)$. Pain scores at one month were also lower in the true acupuncture group than either of the other two groups.

The Chen 2008 study was included in the original review. This was a parallel group study comparing acupuncture to analgesic medication. This paper was written in Chinese and was translated by colleagues within our University Department to obtain a description of the methodology and results. Sixtysix adult participants (age range of 41 to 70 years) with pain associated with 'late' but unspecified cancer were categorised into groups according to pain severity - 'mild', 'moderate' and 'severe'. Participants received either acupuncture applied at three to five 'tender' acupuncture points, or analgesic medication based on the World Health Organization (WHO) three-step principle: aspirin for mild pain, codeine for moderate pain and morphine for severe pain. No placebo control group was included.

Pain intensity was measured by change in VAS score. Participants were categorised into groups according to the change in pain intensity relative to baseline as follows:

- $\quad$ complete relief $=$ VAS changes of $91 \%$ to $100 \%$ reduction in pain intensity from baseline;

- average relief $=$ VAS changes of $61 \%$ to $90 \%$ reduction in pain intensity from baseline;

- partial relief $=$ VAS changes of $31 \%$ to $60 \%$ reduction in pain intensity from baseline;

- no relief = VAS changes of less than $31 \%$ reduction in pain intensity from baseline.

The percentage of participants in each category falling into each of the above categories was calculated and recorded and a cut-off point of pain relief of $31 \%$ or more set as criteria for 
'general effectiveness'. It was concluded that the analgesic effect of acupuncture was significantly more effective than medication, with the total effectiveness of acupuncture reported as $94 \%$ in the acupuncture group and $87.5 \%$ in the medication group ( $\mathrm{P}$ value $<$ 0.05).

It was not possible to extract data from this report because no raw data or standard deviations were reported.

Dang 1998 was included in the original review. This study randomly allocated 48 participants with pain from stomach carcinoma to receive one of three treatments:

- acupuncture (filiform needle), $\mathrm{n}=16$;

- acupuncture point injection with human transfer factor, $n=16$;

- Western medicine (analgesic medication based on the WHO analgesic ladder), $\mathrm{n}=16$

In addition a group of 16 healthy participants were as used as a control. This group did not receive any treatment, and it was assumed that the control group was included for comparison of biochemical data over the course of the study (e.g. leukocyte count). Acupuncture was administered at four to five 'main points' and two to four 'auxiliary points' according to traditional acupuncture points and based on the patient's signs and symptoms. The total treatment period was two months. Treatment was given continuously for two weeks followed by a gap of two to three days before continuing. Each acupuncture treatment course consisted of one treatment per day for grade I pain or two to three sessions per day for grade II or III pain (according to the WHO criteria); needles remained in situ for 20 minutes. For the point injection group an injection of $0.5 \mathrm{ml}$ of freezedried human transfer factor in aqueous solution was administered into four acupuncture points selected in a similar manner to the acupuncture group; this was done twice per week. Participants in the Western medicine group received analgesics including aspirin, indomethacin, AP-237, codeine, dihydrocodeine and dolantin, based on the WHO three-step ladder. Transient effects (30 minutes after treatment) and long-term effects ( 12 hours post-treatment) were calculated for the first 10 days of treatment and the final 10 days of treatment over a two-month period. At each stage of the study participants were categorised into groups according to the effectiveness of treatment: 'markedly effective', 'improved' and 'ineffective'. The percentage of participants in the 'markedly effective' and 'improved' categories groups was used as a measure of effectiveness. No explanation was given about how pain was measured and how participants were categorised into these groups in either paper.

The results indicated that medication provided more effective analgesia during the first 10 days of treatment for both transient and long-term effects. During the final 10 days of treatment the transient effects of the acupuncture and point injection group were similar to the medication group and the long-term effects were equal ( $P$ value $>0.05)$. However, the long-term 'markedly effective' scores for the acupuncture (48.8\%) and point injection $(51.9 \%)$ groups during the final 10 days of treatment were significantly higher than those for the medication group (33.8\%) (both P values $<0.05)$.

The Chen 2013 study was included in this update, but not in the original review. This was a parallel group study of acupuncture-naive adults with pancreatic cancer pain that compared electroacupuncture $(n=30)$ with placebo $(n=30)$. Treatment occurred daily, for 30 minutes, over a period of three days. Acupuncture was applied bilaterally at Jiaji points T8 to T12. The intervention group was compared with a sham acupuncture group that used non-penetrative needles. Outcomes were pain after the three days of treatment and two days later as measured on a numerical rating scale (NRS).

The results indicated a significant difference between the two groups after three days of treatment ( $P$ value $<0.001$ ), and two days post-treatment there was a significant reduction in pain intensity reduction between the groups ( $P$ value $<0.001$ ). Blinding was not reported so it was not possible to exclude a risk of bias in this study.

The authors concluded that electroacupuncture was an effective treatment for relieving pancreatic cancer pain.

We included Lu 2012 in this update, but not in the original review. This parallel group pilot study included 21 women with newly diagnosed and recurrent primary ovarian or peritoneal cancer, cancer of the uterus, or tumours of the fallopian tubes. This was a report on the secondary objective of a larger study investigating chemotherapy-induced neutropaenia. The objective of this pilot study was to determine the effects of acupuncture on quality of life scores, which included pain.The participants were randomised into two groups:
- electroacupuncture $(n=11)$
- sham electroacupuncture $(n=10)$

Acupuncture began in the week prior to the second cycle of chemotherapy and 10 sessions were conducted with two to three sessions per week for both groups. The acupuncture group received electroacupuncture at nine acupuncture points bilaterally (17 needles) at $20 \mathrm{~Hz}$ to $25 \mathrm{~Hz}$ with needles inserted to a depth of $10 \mathrm{~mm}$ for 30 minutes. The aim of the acupuncturist was to achieve a needle sensation. The sham group received acupuncture at five non-acupuncture points bilaterally (nine needles) with the electroacupuncture unit switched off; needles were inserted to a depth of less than $0.2 \mathrm{~mm}$ for 30 minutes with no needle sensation permitted. Study outcomes were measured using the European Organisation for Research and Treatment of Cancer (EORTC) quality of life questionnaire QLQ-C30, and the ovarian cancer questionnaire QLQ-OV28. The QLQ-C30 questions included pain scores taken at baseline and during the second recovery period.

The results indicated that although there was an improvement in quality of life scores for pain in the second recovery period compared with baseline, this occurred in both groups and there was no significant difference between groups. The authors did not draw any conclusions from the study because of the small sample size, except that it was feasible to conduct this study design amongst a similar patient group.

A summary of the five included studies can be found in Table 1.

\section{Excluded studies}

Thirteen studies were excluded in the previous version of this review, and we excluded an additional four at this update stage. Most of the papers identified through our searches as investigating acupuncture for cancer pain did not contain clinical data. Initially, we included two of the three studies that were not written in English 
(Meng 2002; Nguyen 2005), as a translation was not available at the initial screening. However, we obtained translated abstracts at a later date, which enabled us to exclude these studies, as neither were clinical trials. We excluded three studies because they were not randomised (Aung 1994; Guo 1995; Hu 2011), and Xia 1986 after discussion, because pain was not a primary outcome measure and some of the participants were suffering from postoperative pain. Poulain 1985 was also a study of postoperative pain and was excluded on this basis. The studies by Carr 2002 and Goudas 2001 were narrative reviews of the evidence and Yu 1992 was a discussion paper. Minton 2007 was a letter, although this was not clear in the initial screening by title and abstract. The study by Zhang 2006 fitted many of the inclusion criteria, but was a study of herbal medicine for cancer pain with no acupuncture. We excluded the Liu 2010 study as it involved giving a strong analgesic injection at an acupuncture points, similarly, the Wang 2010 study involved injections of angelica and so was also excluded. We excluded the He 2013 study because it included injections of stauntoniae at acupoints and administration of transdermal fentanyl as part of the study.
A search conducted just prior to publication of the original review identified two further studies that were potentially eligible (Akhileswaran 2010; Sima 2009). Both of these studies were only available as conference abstracts with no traceable published papers and therefore did not meet our inclusion criteria. Contact details for the authors were not provided in either of the abstracts. Nevertheless, the work conducted by Sima 2009 is worthy of mention because it provides some clinical data from an RCT that investigated the effects of electroacupuncture on neuropathic pain and other measures in patients with metastatic breast and lung cancer. The study found that acupuncture alleviated neuropathic bone pain and decreased consumption of analgesics compared with a control group receiving acupuncture on non-acupuncture points. However, insufficient information was available within the abstract about the control group intervention.

\section{Risk of bias in included studies}

We determined the Cochrane 'Risk of bias' score for each trial and this information is summarised in Figure 2 and Figure 3. None of the trials identified in this review had adequate sample sizes and only the Lu 2012 study had adequate blinding. 
Figure 2. Methodological quality summary: review authors' judgements about each methodological quality item for each included study

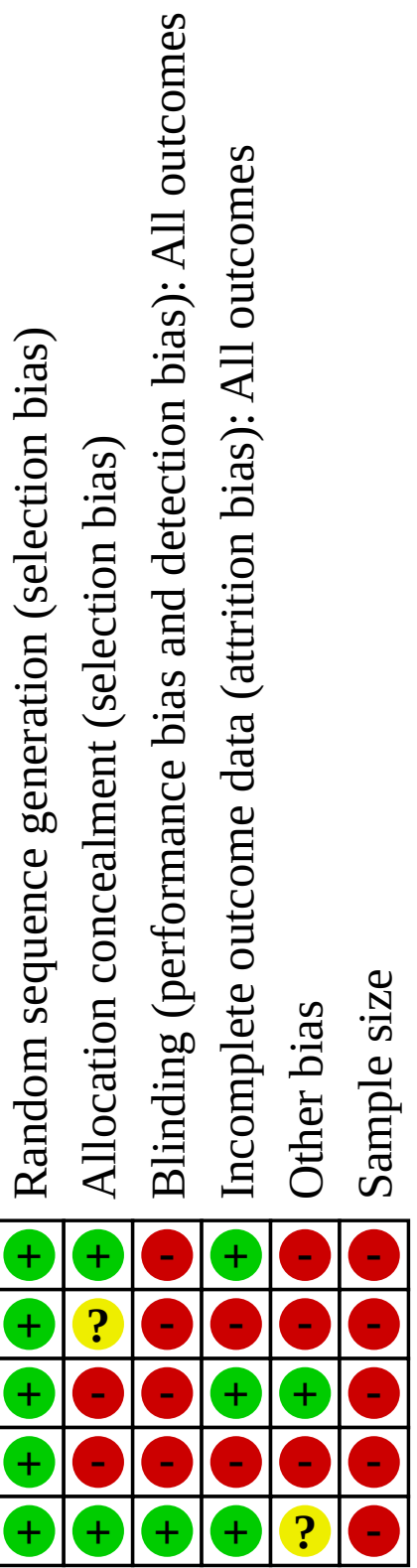


Figure 3. Risk of bias graph: review authors' judgements about each risk of bias item presented as percentages across all included studies

Random sequence generation (selection bias)

Allocation concealment (selection bias)

Blinding (performance bias and detection bias): All outcomes Incomplete outcome data (attrition bias): All outcomes

Other bias

Sample size

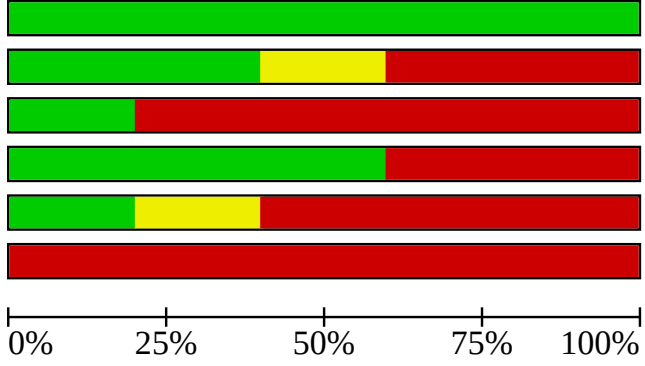

Low risk of bias

Unclear risk of bias

High risk of bias

\section{Effects of interventions}

Alimi 2003 found a significant decrease in pain intensity recorded on VAS at one month and two months. Participants in the true acupuncture group had significantly lower pain scores at two months than either the placebo acupuncture or ear seeds group ( $P$ value $<0.001$ ) with an overall $36 \%$ decrease in pain intensity as measured on a VAS. There was little change in pain intensity recorded for the placebo acupuncture group (2\%). Analgesic use was reported in a self-report diary and was found to be stable during the period of the study. The authors did not report on any other outcome measures such as patient satisfaction, quality of life or hospital admissions. They reported that there were no adverse events as a result of treatment.

Chen 2008 reported that acupuncture was more effective (94.1\%) than medication (87.5\%; $P$ value $<0.05$ ). The percentage of participants showing an improvement in VAS scores of $31 \%$ or more was used as a measure of 'general effectiveness' and the difference was tested again using the $\mathrm{Chi}^{2}$ test. These results should be treated with caution as the description and reporting of the study were unclear and the method of analysis debatable. The study did not report on any other outcome measures such as patient satisfaction, quality of life, hospital admissions or adverse events.

Chen 2013 found that after three treatments of acupuncture, pain intensity measured using an NRS decreased compared with baseline in the electroacupuncture group $(-1.67,95 \% \mathrm{Cl}-1.46$ to $-1.87)$, while there was little change in the control group $(-0.13$, $95 \% \mathrm{Cl} 0.08$ to -0.35$)$. The difference between the two groups was statistically significant at three days $(P$ value $<0.001)$. There was also a significant difference between the two groups at a twoday post-treatment follow-up ( $P$ value $<0.001$ ). The study did not report on any other outcome measures such as patient satisfaction, quality of life or hospital admissions. Participants were asked to record analgesic consumption and any adverse events, but use of analgesia was not reported in the results. No adverse events were reported as a result of treatment. The authors concluded that electroacupuncture is an effective treatment for relieving pancreatic cancer pain.

Dang 1998 used analgesic consumption as a primary outcome measure. No validated pain scales were used. The authors reported that the Western medication group experienced more effective immediate analgesia during the first 10 days than the filiform needle or point injection groups, but by the final 10 days the effects were similar. There were no significant differences between the groups in either transient or long-term effects. The use of ordinal categories for pain relief without specifying parameters make additional comparisons of trial data meaningless. Also, the pain outcomes in this study were linked to improving sleep and other quality of life criteria which presents a confusing picture. Adverse events were not reported in this study.

Lu 2012 reported that quality of life sub scores on the EORTCQLQ-C30 improved in the acupuncture arm, including the mean score for pain ( $P$ value 0.05 ), but after adjusting for baseline differences pain was not significantly improved when compared with sham acupuncture. The only significant difference in quality of life was the measure of social functioning. This study was a pilot investigating the feasibility of conducting a larger trial, and was therefore relatively small. The results for pain were inconclusive. The study did not report on any other outcome measures such as patient satisfaction, analgesic consumption, hospital admissions or adverse events.

\section{DISCUSSION}

\section{Summary of main results}

This updated review illustrates how few studies of acupuncture for cancer pain exist. Three studies were included in the original review and an additional two studies included in this update. Of the included studies, Chen 2013 reported benefits of acupuncture in managing pancreatic cancer pain; Lu 2012 reported no difference between real and sham electroacupuncture for pain associated with ovarian cancer; Chen 2008 reported benefits of acupuncture over conventional medication for late stage unspecified cancer; Alimi 2003 reported benefits for auricular (ear) acupuncture over placebo for chronic neuropathic pain related to cancer; and Dang 1998 reported no differences between conventional analgesia and acupuncture within the first 10 days of treatment for stomach carcinoma, although they suggested that acupuncture increased long-term analgesic effect over Western medicine during the final 10 days of treatment over a two-month period. The heterogeneity of methodologies, cancer populations and techniques used in the included studies precluded pooling of data and therefore metaanalysis was not carried out. A subgroup analysis on acupuncture for CIBP was not conducted because none of the studies made any reference to bone pain. 
When adequacy of acupuncture dose was examined, Alimi 2003 reported the use of an average of six auricular points and an average treatment duration was 44 minutes. This partially meets the criteria for adequacy suggested by White 2007, but it was unclear how many treatments were carried out and needle sensation was not reported. The studies by Chen 2013 and Lu 2012 used 10 and 17 needle sites respectively in their intervention groups, and although Chen 2013 reported only three treatment sessions, Lu 2012 carried out 10 sessions at a frequency of two to three per week. Both these studies reported a treatment duration of 30 minutes. Chen 2008 used less than six needles and did not report the frequency of treatment sessions and Dang 1998 reported adequate duration, frequency and points used, but the frequency of treatment varied upon the level of pain reported. Reference was made to achieving 'de qi' (needle sensation) in two of the studies (Dang 1998; Lu 2012). Dang 1998 also emphasised the need for participants to concentrate the mind on the diseased site to promote needle sensation.

All five studies had a low risk of bias associated with random sequence generation, but only three studies had a low risk of bias associated with incomplete outcome data, two studies had a low risk of bias associated with allocation concealment and one study had a low risk of bias associated with inadequate blinding. In the four studies with inadequate blinding there was an increased possibility of observational bias. All of the included studies had a high risk of bias associated with inadequate sample size, which predisposes them to statistical type II errors and makes it difficult to draw any conclusions related to efficacy.

It was not possible to pool data for meta-analysis due to heterogeneity, and this also precluded sensitivity analysis.

\section{AUTHORS' CONCLUSIONS}

\section{Implications for practice}

\section{For patients with cancer pain}

There is not enough evidence to be able to conclude that acupuncture is effective for treating cancer pain, although some small studies contain evidence which is promising. Since the last version of this review, none of the new relevant studies have provided additional information to change these conclusions. Some patients use acupuncture for its other benefits (Garcia 2013; Lian 2014; Qaseem 2008), and as acupuncture is an intervention with few side-effects, it can be used, provided that patients are aware of its limitations.

\section{For practitioners}

There is insufficient evidence to provide a judgement on whether acupuncture is effective in treating cancer pain in adults. Nevertheless, acupuncture continues to be used quite widely for cancer pain and for other cancer-related conditions (Garcia 2013; Lian 2014; Qaseem 2008). As peer-reviewed guidelines exist for the use of acupuncture in cancer patients (Filshie 2006), it is suggested that practitioners follow these guidelines and that patients are made aware of the potential limitations of this type of intervention.

\section{For policy-makers and funders}

The available evidence does not yet suggest that acupuncture is effective for treating cancer pain, although it has been used with some success in other cancer-related conditions such as vasomotor symptoms that occur as a result of cancer treatments (Harding 2009; Lian 2014), and chemotherapy-induced nausea and vomiting (Chao 2009).

\section{Implications for research}

Acupuncture is widely used to treat cancer-related pain, but the available evidence is of low quality. Therefore a judgement on whether acupuncture is effective cannot be made. Trials of acupuncture comparing it with placebo interventions which control for patients' expectations and beliefs about the effects of treatment have been used to determine whether acupuncture has specific effects over and above a placebo response (Ernst 2004; Ernst 2006; Johnson 2006). However, findings have been inconsistent and there is an ongoing debate as to whether placebo acupuncture is appropriate as a control because it may not be physiologically inert and could be as effective as true acupuncture (Lund 2009; Lundeberg 2008). Therefore pragmatic trials of the effectiveness of acupuncture on cancer pain compared with standard treatment may provide useful information (Lundeberg 2009), but attention should be given to ensuring an adequate dose of acupuncture is given in line with current recommendations (White 2008). As no studies investigating acupuncture for cancerinduced bone pain were identified, this is an area that should be specifically targeted for further research.

The design of future randomised controlled trials in this area should include:

- power calculations to ensure adequate sample sizes;

- homogeneity of cancer pain conditions under study;

- use of optimal dose of acupuncture;

- assessor blinding;

- use of valid and reliable pain outcome measures;

- details about the nature of the control used.

\section{ACKNOWLEDGEMENTS}

The review authors are affiliated to the Leeds Pallium Research Group (www.leeds.ac.uk/pallium/index.htm).

\section{Cochrane Review Group funding acknowledgement}

The National Institute for Health Research (NIHR) is the largest single funder of the Cochrane PaPaS Group. Disclaimer: The views and opinions expressed therein are those of the authors and do not necessarily reflect those of the NIHR, National Health Service (NHS) or the Department of Health. 


\section{R E F E R E N C E S}

\section{References to studies included in this review}

\section{Alimi 2003 \{published data only\}}

Alimi D, Rubino C, Pichard-Leandri E, Fermand-Brule S, Dubreuil-Lemaire M, Hill C. Analgesic effect of auricular acupuncture for cancer pain: a randomized, blinded, controlled trial. Journal of Clinical Oncology 2003;21(22):4120-6.

\section{Chen 2008 \{published data only\}}

Chen ZJ, Guo YP, Wu ZC. Observation on the therapeutic effect of acupuncture at pain points on cancer pain. Zhongguo Zhen Jiu [Chinese Acupuncture \& Moxibustion] 2008;28(4):251-3.

\section{Chen 2013 \{published data only\}}

Chen H, Liu TY, Zhu J, Wu CJ, Liu LM. Electroacupuncture treatment for pancreatic cancer pain: a randomized controlled trial. Pancreatology 2013;13(6):594-7.

\section{Dang 1998 \{published data only\}}

* Dang W, Yang J. Clinical study on acupuncture treatment of stomach carcinoma pain. Journal of Traditional Chinese Medicine / Chung i Tsa Chih Ying Wen Pan 1998;18(1):31-8.

Dang W. Pain of gastric carcinoma treated by acupuncture. International Journal of Acupuncture 1997;8(3):241-8.

\section{Lu 2012 \{published data only\}}

Lu W, Matulonis UA, Dunn JE, Lee H, Doherty-Gilman A, DeanClower $E$, et al. The feasibility and effects of acupuncture on quality of life scores during chemotherapy in ovarian cancer: results from a pilot, randomized sham-controlled trial. Medical Acupuncture 2012;24(4):233-40.

\section{References to studies excluded from this review}

\section{Akhileswaran 2010 \{published data only\}}

Akhileswaran R, Lim WT, Ong S, Tong FH, Tan SB, Tan H, et al. A randomized controlled trial (RCT) using different acupuncture techniques for better pain relief in hospice patients with chronic cancer pain. In: 3rd International Conference on Neuropathic Pain. Vol. 4. 2010:128

\section{Aung 1994 \{published data only\}}

Aung S. The clinical use of acupuncture in oncology: symptom control. Acupuncture in Medicine 1994;12(1):37-40.

\section{Carr 2002 \{published data only\}}

Carr D, Goudas L, Lawrence D, Pirl W, Lau J, DeVine D, et al. Management of cancer symptoms: pain, depression, and fatigue: evidence report/technology assessment. Agency for Healthcare Research and Quality Evidence Report No. 61 2002;61:1-5.

\section{Goudas 2001 \{published data only\}}

Goudas L, Carr DB, Bloch R, Balk E, Ioannidis JP, Terrin N, et al. Management of cancer pain. Agency for Healthcare Research and Quality Evidence Report No. 35 2001;1(35):1-5.
Guo 1995 \{published data only\}

Guo R, Zhang L, Gong Y, Zhang B. The treatment of pain in bone metastasis of cancer with the analgesic decoction of cancer and the acupoint therapeutic apparatus. Journal of Traditional Chinese Medicine / Chung i Tsa Chih Ying Wen Pan 1995;15(4):262-4

\section{He 2013 \{published data only\}}

He l, Tian F. Clinical observation of auricular acupuncture and acupoint injection combined with transdermal fentanyl application in the treatment of cancer pain. International Journal of Clinical Acupuncture 2013;22(2):51-4.

\section{Hu 2011 \{published data only\}}

Hu J, Qu XD. Effect of traditional Chinese medicine combined with acupoint injection to pain in patients with advanced liver cancer. Hubei Journal of Traditional Chinese Medicine 2011;1:41-2.

\section{Liu 2010 \{published data only\}}

Liu HF. Efficacy and care of acupoint injection therapy for abdominal pain of cancer. Journal of Emergency in Traditional Chinese Medicine 2010;19(3):527-8.

\section{Meng 2002 \{published data only\}}

Meng A. Acupuncture in oncology. Traditional Chinese medicine (TCM) as an additional method. Schweizerische Zeitschrift für Ganzheitsmedizin / Swiss Journal of Integrative Medicine 2002;14(3):158-64

\section{Minton 2007 \{published data only\}}

Minton $\mathrm{O}$, Higginson IJ. Electroacupuncture as an adjunctive treatment to control neuropathic pain in patients with cancer. Journal of Pain and Symptom Management 2007;33(2):115-7.

Nguyen 2005 \{published data only\}

Nguyen J. Analgesic effect of auricular acupuncture for cancer pain: a randomised, blinded, controlled trial. Acupuncture et Moxibustion 2005;4(2):144-6.

Poulain 1985 \{published data only\}

Poulain P, Laplanche A, Pichard E. A randomized study of stimulation-produced and acupuncture analgesia versus pre and postoperative classical analgesia in patients with cancer Bull Cancer (Paris) 1985;72(4):342.

Sima 2009 \{published data only\}

Sima L, Yin C. Efficacy of electroacupuncture for bone metastatic cancer patients with neuropathic pain: a randomized controlled trial. In: Journal of Clinical Oncology (Meeting Abstracts). Vol. 27. 2009:9534

\section{Wang 2010 \{published data only\}}

Wang S-C, Yin H-B, Li W-F. Acupuncture combined with point injection of Chinese angelica injection for pain of advanced stomach carcinoma.. Chinese Journal of Cancer Prevention and Treatment 2010;18:1487-9. 
Xia 1986 \{published data only\}

Xia Y, Zhang D, Yang C, Xu H, Li Y, Ma L. An approach to the effect on tumors of acupuncture in combination with radiotherapy or chemotherapy. Journal of Traditional Chinese Medicine / Chung $i$ Tsa Chih Ying Wen Pan 1986;6:23-6.

Yu 1992 \{published data only\}

Yu G. Control of cancer pain to ensure the best possible quality of life. Journal of Traditional Chinese Medicine / Chung i Tsa Chih Ying Wen Pan 1992;12(4):243-55.

\section{Zhang 2006 \{published data only\}}

Zhang T, Ma S, Xie L, Deng G, Tang QH, Pan ZZ, et al. Clinical research on nourishing yin and unblocking meridians recipe combined with opioid analgesics in cancer pain management. Chinese Journal of Integrative Medicine 2006;12(2):180-4.

\section{Additional references}

\section{Bao 2014}

Bao Y, Kong X, Yang L, Liu R, Shi Z, Li W, et al. Complementary and alternative medicine for cancer pain: an overview of systematic reviews. Evidence-Based Complementary And Alternative Medicine: Ecam 2014;2014(http:// dx.doi.org/10.1155/2014/170396):9.

\section{Bardia 2006}

Bardia A, Barton DL, Prokop LJ, Bauer BA, Moynihan TJ. Efficacy of complementary and alternative medicine therapies in relieving cancer pain: a systematic review. Journal of Clinical Oncology 2006;24:5457-64.

\section{Bjordal 2007}

Bjordal JM, Johnson MI, Lopes-Martins RAB, Bogen B, Chow R, Ljunggren $A E$. Short-term efficacy of physical interventions in osteoarthritic knee pain. A systematic review and meta-analysis of randomised placebo-controlled trials. BMC Musculoskeletal Disorders/www.biomedcentral.com 2007;8(51).

\section{Brainin-Mattos 2006}

Brainin-Mattos J, Smith ND, Malkmus S, Rew Y, Goodman M, Taulane J, et al. Cancer-related bone pain is attenuated by a systemically available delta-opioid receptor agonist. Pain 2006;122(1-2):174-81.

\section{Cata 2006}

Cata JP, Weng HR, Reuben JM, Dougherty PM. Clinical and experimental findings in humans and animals with chemotherapy-induced peripheral neuropathy. Minerva Anestesiologica 2006;72(3):151-69.

\section{Chao 2009}

Chao, Li-FenZhang, Anthony LinLiu, Hsueh-ErhCheng, MingHueiLam, Hung-BunLo, Sing Kai. The efficacy of acupoint stimulation for the management of therapy-related adverse events in patients with breast cancer: a systematic review. Breast cancer research and treatment 2009;118(2):255-67.

\section{Choi 2012}

Choi T-Y, Lee M, Kim TH, Zaslawski C, Ernst E. Acupuncture for the treatment of cancer pain: a systematic review of randomised clinical trials. Supportive Care in Cancer 2012;20(6):1147-58

\section{Coleman 2001}

Coleman RE. Metastatic bone disease: clinical features, pathophysiology and treatment strategies. Cancer Treatment Reviews 2001;27:165-76.

\section{Dang 1997}

Dang W. Pain of gastric carcinoma treated by acupuncture. International Journal of Acupuncture 1997;8(3):241-8.

\section{Davis 2008}

Davis MA, Kononowech RW, Rolin SA, Spierings EL. Acupuncture for tension-type headache: a meta-analysis of randomized, controlled trials. Pain 2008;9(8):667-77.

\section{Derry 2006}

Derry CJ, Derry S, McQuay HJ, Moore RA. Systematic review of systematic reviews of acupuncture published 1996-2005. Clinical Medicine 2006;6(4):381-6.

\section{Dillon 1999}

Dillon M, Lucas C. Auricular stud acupuncture in palliative care patients. Palliative Medicine 1999;13(3):253-4

\section{Ernst 2004}

Ernst E. Acupuncture: who is missing the point? Pain 2004:109:203-4.

\section{Ernst 2006}

Ernst E. Acupuncture - a critical analysis. Journal of Internal Medicine 2006;259(2):125-37.

\section{Ezzo 2000}

Ezzo J, Berman B, Hadhazy V, Jadad AR, Lao L, Singh BB. Is acupuncture effective for the treatment of chronic pain? A systematic review. Pain 2000;86(3):217-25.

\section{Filshie 1990}

Filshie J. Acupuncture for malignant pain. Acupuncture in Medicine 1990;8(2):38-9.

\section{Filshie 2004}

Filshie J, Rubino C. Promising results of auriculoacupuncture in the treatment of cancer pain. Focus on Alternative \& Complementary Therapies 2004;9(2):132-3.

\section{Filshie 2006}

Filshie J, Hester J. Guidelines for providing acupuncture treatment for cancer patients - a peer-reviewed sample policy document. Acupuncture in Medicine 2006;24(4):172-82.

\section{Furlan 2005}

Furlan AD, van Tulder MW, Cherkin DC, Tsukayama H, Lao L, Koes BW, et al. Acupuncture and dry-needling for low back pain: an updated systematic review within the framework of the Cochrane Collaboration. Spine 2005;30(8):944-63. 


\section{Garcia 2013}

Garcia MK, McQuade J, Haddad R, Patel S, Lee R, Yang P, et al. Systematic review of acupuncture in cancer care: a synthesis of the evidence. Journal Of Clinical Oncology 2013;31(7):952-60.

\section{Gralow 2007}

Gralow J, Tripathy D. Managing metastatic bone pain: the role of bisphosphonates. Journal of Pain \& Symptom Management 2007;33(4):462-72.

\section{Green 2005}

Green S, Buchbinder R, Hetrick S. Acupuncture for shoulder pain. Cochrane Database of Systematic Reviews 2005, Issue 2. Art. No: CD005319. [DOI: 10.1002/14651858.CD005319]

\section{Harding 2009}

Harding C, Harris A, Chadwick D. Auricular acupuncture: a novel treatment for vasomotor symptoms associated with luteinizinghormone releasing hormone agonist treatment for prostate cancer. BJU International 2009;103(2):186-190.

\section{He 2004}

He D, Veiersted K, Hostmark AT, Medbo Jl. Effect of acupuncture treatment on chronic neck and shoulder pain in sedentary female workers: a 6-month and 3-year follow-up study. Pain 2004;109:299-307.

\section{Higgins 2011}

Higgins JPT, Green S (editors). Cochrane Handbook for Systematic Reviews of Interventions Version 5.1.0 (updated March 2011). The Cochrane Collaboration, 2011. Available from www.cochrane-handbook.org.

\section{Hopwood 2004}

Hopwood V. Acupuncture in Physiotherapy. Butterworth Heinemann, 2004.

\section{Johnson 2006}

Johnson MI. The clinical effectiveness of acupuncture for pain relief - you can be certain of uncertainty. Acupuncture in Medicine 2006;24:71-9.

\section{Keskinbora 2007}

Keskinbora K, Pekel AF, Aydinli I. Gabapentin and an opioid combination versus opioid alone for the management of neuropathic cancer pain: a randomized open trial. Journal of Pain and Symptom Management 2007;34(2):183-9.

\section{Kwon 2006}

Kwon YD, Pittler MH, Ernst E. Acupuncture for peripheral joint osteoarthritis. Rheumatology 2006;45(11):1331-7.

\section{Laird 2008}

Laird B, Colvin MF. Management of cancer pain: basic principles and neuropathic cancer pain. European Journal of Cancer 2008;44:1078-82.

\section{Lee 2005}

Lee H, Schmidt K, Ernst E. Acupuncture for the relief of cancerrelated pain - a systematic review. European Journal of Pain 2005;9(4):437-44.

\section{Lian 2014}

Lian W-L, Pan M-Q, Zhou D-H, Zhang ZJ. Effectiveness of acupuncture for palliative care in cancer patients: a systematic review. Chinese Journal of Integrative Medicine 2014;20(2):136-47.

\section{Lipton 2004}

Lipton A. Pathophysiology of bone metastases: how this knowledge may lead to therapeutic intervention. Supportive Oncology 2004;2(3):205-13.

\section{Lund 2009}

Lund I, Näslund J, Lundberg T. Minimal acupuncture is not a valid placebo control in randomised controlled trials of acupuncture: a physiologist's perspective. Chinese Medicine 2009;4(1):1-9.

\section{Lundeberg 2008}

Lundeberg T, Lund I, Näslund J, Thomas M. The Emperors sham - wrong assumption that sham needling is sham. Acupuncture in Medicine 2008;26(4):239-42.

\section{Lundeberg 2009}

Lundeberg T, Lund I, Sing A, Näslund J. Is placebo acupuncture what it is intended to be? Evidence-based Complementary and Alternative Medicine 2009; Jun 12:[Epub ahead of print].

\section{MacPherson 2007}

MacPherson H, Hammerschlag R, Lewith G, Schnyer R. Acupuncture Research. Churchill Livingstone, 2007.

\section{Manheimer 2005}

Manheimer E, White A, Berman B, Forys K, Ernst E. Metaanalysis: acupuncture for low back pain. Annals of Internal Medicine 2005;142(8):651-63.

\section{Manheimer 2007}

Manheimer E, Linde K, Loa L, Bouter LM, Berman BM. Metaanalysis: acupuncture for osteoarthritis of the knee. Annals of Internal Medicine 2007;146(12):868-77.

\section{Payne 1998}

Payne R, Paice JB. Cancer pain clinical practice guidelines for clinicians and patients: rationale, barriers to implementation and future directions. In: Payne R, Patt R, Stratton Hill C, editors(s). Assessment and Treatment of Cancer Pain. Seattle: IASP Press, 1998.

\section{Petrut 2008}

Petrut B, Trinkaus M, Simmons C, Clemons M. A primer of bone metastases management in breast cancer patients. Current Oncology 2008;15 (supplement 1):S50-7.

\section{Qaseem 2008}

Qaseem A, Snow V, Shekelle P, Casey D, Cross JT, Owens D. Evidence-based interventions to improve the palliative care of pain, dyspnea, and depression at the end of life: a clinical practice guideline from the American College of Physicians. Annals of Internal Medicine 2008;148(2):141-6. 


\section{RevMan 2014 [Computer program]}

The Nordic Cochrane Centre, The Cochrane Collaboration Review Manager. Version Version 5.3. Copenhagen: The Nordic Cochrane Centre, The Cochrane Collaboration, 2014.

\section{Ripamonti 2000}

Ripamonti C, Fulfaro F. Malignant bone pain: pathophysiology and treatments. Current Review of Pain 2000;4(3):187-96.

\section{Rosier 1998}

Rosier R, Hicks D, Teot L, Puzas JE, O'Keefe R. Mechanisms of bone metastasis. In: Payne R, Patt R, Stratton Hill C, editors(s). Assessment and Treatment of Cancer Pain. Seattle: IASP Press, 1998.

\section{Strong 2002}

Strong J, Bennett S. Cancer pain. In: Strong J, Unruh AM, Wright A, Baxter GD, editors(s). Pain: A Textbook for Therapists. Churchill Livingstone, 2002:411-23.

\section{Sun 2008}

Sun Y, Gan TJ, Dubose JW, Habib AS. Acupuncture and related techniques for postoperative pain: a systematic review of randomized controlled trials. British Journal of Anaesthesia 2008;101(2):151-60.

\section{Towler 2013}

Towler P, Molassiotis A, Brearley SG. What is the evidence for the use of acupuncture as an intervention for symptom management in cancer supportive and palliative care: an integrative overview of reviews. Supportive Care In Cancer 2013;21(10):2913-23.

\section{Trinh 2006}

Trinh KV, Graham N, Gross AR, Goldsmith CH, Wang E, Cameron ID, et al. Acupuncture for neck disorders. Cochrane Database of Systematic Reviews 2006, Issue 3. Art. No: CD004870. [DOI: 10.1002/14651858.CD004870.pub3]

\section{Twycross 2008}

Twycross R, Bennett M. Cancer pain syndromes. In: Sykes N, Bennett MI, Yuan C-S, editors(s). Cancer Pain. Clinical Pain Management. 2nd edition. London: Hodder Arnold, 2008:27-37.

\section{Urch 2008}

Urch C E, Suzuki R. Pathophysiology of somatic, visceral, and neuropathic cancer pain. In: Sykes N, Bennett MI, Yuan C-S, editors(s). Cancer Pain: Clinical Pain Management. 2nd edition. London: Hodder Arnold, 2008:3-12.

\section{Vallerand 2007}

Vallerand AH, Templin T, Hasenau SM, Riley-Doucet C. Factors that affect functional status in patients with cancer-related pain. Pain 2007;132(1-2):82-90.

\section{van den Beuken-van Everdingen 2007a}

van den Beuken-van Everdingen MHJ, de Rijke JM, Kessels AG, Schouten HC, van Kleef M, Patijn J. Prevalence of pain in patients with cancer: a systematic review of the past 40 years. Annals of Oncology: Official Journal of the European Society for Medical Oncology/ESMO 2007;18(9):1437-49.

\section{van den Beuken-van Everdingen 2007b}

van den Beuken-van Everdingen MHJ, de Rijke JM, Kessels AG, Schouten HC, van Kleef M, Patijn J. High prevalence of pain in patients with cancer in a large population-based study in the Netherlands. Pain 2007;132(3):312-20.

\section{White 2007}

White A, Foster NE, Cummings M, Barlas P. Acupuncture treatment for chronic knee pain: a systematic review. Rheumatology 2007;46(3):384-90.

\section{White 2008}

White A, Cummings M, Barlas P, Cardini F, Filshie J, Foster NE, et al. Defining an adequate dose of acupuncture using a neurophysiological approach - a narrative review of the literature. Acupuncture in Medicine 2008;26(2):111-20.

* Indicates the major publication for the study

\section{CHARACTERISTICS OF STUDIES}

Characteristics of included studies [ordered by study ID]

Alimi 2003

\section{Study characteristics}

\begin{tabular}{ll}
\hline Methods & RCT, 3 arms \\
\hline Participants & $\begin{array}{l}90 \text { adult participants with cancer pain } \geq 30 \mathrm{~mm} \text { on VAS for at least } 1 \text { month. Excluded if had had } \\
\text { acupuncture before. Age range 37-84 years. All participants were on stable analgesia }\end{array}$ \\
\hline Interventions & $\begin{array}{l}\text { Group 1: } 2 \text { treatments of auricular acupuncture at points selected according to electrodermal response } \\
(\mathrm{n}=29)\end{array}$ \\
Group 2: auricular acupuncture at placebo points $(\mathrm{n}=30)$
\end{tabular}


Alimi 2003 (Continued)

Group 3: auricular seeds at placebo points $(n=31)$

\begin{tabular}{ll}
\hline Outcomes & Pain on VAS \\
& Pain after 1 month and 2 months \\
Average electrical potential differences at 1 and 2 months
\end{tabular}

Notes Analgesic medication recorded in self-report diary

\section{Risk of bias}

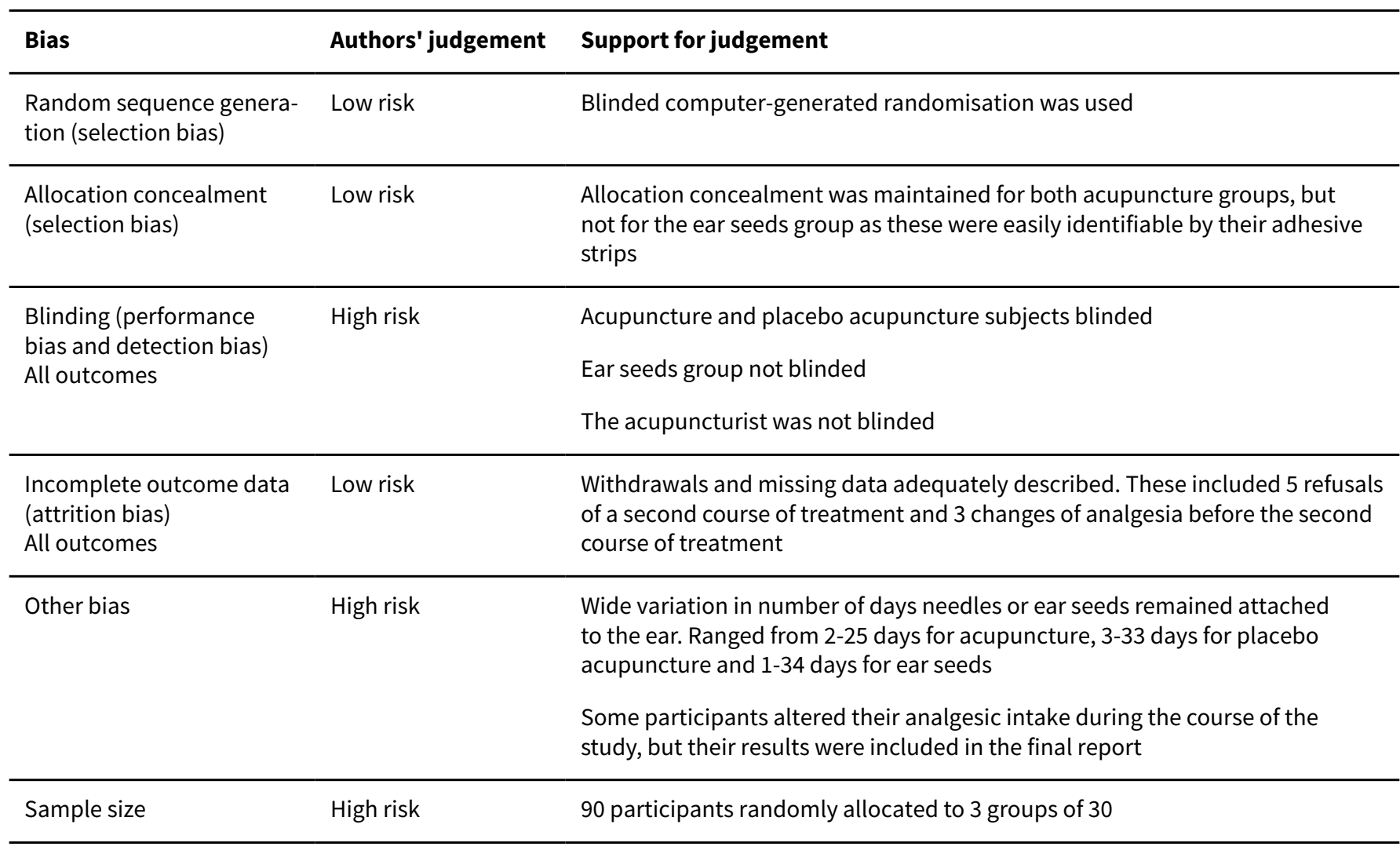

Chen 2008

\section{Study characteristics}

\begin{tabular}{ll}
\hline Methods & RCT, 3 arms \\
\hline Participants & 66 participants with cancer pain randomised to 3 groups: 'mild pain', 'moderate pain' and 'severe pain' \\
& Each of these 3 pain groups randomly divided into an acupuncture group and an oral medication group \\
\hline Interventions & Group 1: acupuncture \\
& Group 2: oral medication group according to WHO 3 step administration in which participants in: \\
• mild pain were given aspirin \\
- moderate pain were given codeine \\
- severe pain were given morphine
\end{tabular}


Chen 2008 (Continued)

Outcomes
Pain scores measured on a VAS, with response percentage calculated as [(score before-score after)/score before] $\times 100$

Analgesic effect reported from percentage difference in pain score. Complete relief (CR) $91 \%-100 \%$, average relief (AR) 61\%-90\%, partial relief (PR) 31\%-60\%, or no relief (NR) $>31 \%$

\begin{tabular}{ll}
\hline Notes & Translated from Chinese \\
\hline
\end{tabular}

\section{Risk of bias}

\begin{tabular}{lll}
\hline Bias & Authors' judgement & Support for judgement \\
\hline $\begin{array}{l}\text { Random sequence genera- } \\
\text { tion (selection bias) }\end{array}$ & Low risk & $\begin{array}{l}\text { Randomisation tables used to allocate subjects to the acupuncture or medica- } \\
\text { tion groups. It was not clear whether randomisation was carried out by blind- } \\
\text { ed personnel }\end{array}$ \\
\hline $\begin{array}{l}\text { Allocation concealment } \\
\text { (selection bias) }\end{array}$ & Unclear risk & Allocation concealment was not clearly stated \\
\hline $\begin{array}{l}\text { Blinding (performance } \\
\text { bias and detection bias) }\end{array}$ & High risk & Participant and evaluator blinding not described \\
\hline $\begin{array}{l}\text { All outcomes } \\
\text { (attrition bias) } \\
\text { All outcomes }\end{array}$ & High risk & Incomplete data and withdrawals not described \\
\hline $\begin{array}{l}\text { Other bias } \\
\text { Sample size }\end{array}$ & High risk & Poor reporting of intervention and methodology \\
\hline
\end{tabular}

Chen 2013

\section{Study characteristics}

\begin{tabular}{ll}
\hline Methods & RCT 2 arms \\
\hline Participants & $\begin{array}{l}60 \text { participants with pancreatic cancer pain randomised to } 2 \text { groups: electroacupuncture group ( } \mathrm{n}=30) \\
\text { and placebo needle group }(\mathrm{n}=30)\end{array}$ \\
\hline Interventions & $\begin{array}{l}\text { Group 1: electroacupuncture at a frequency of 2/100 Hz and a current of } 1 \mathrm{~mA} \text { with a disperse-dispense } \\
\text { waveform }\end{array}$ \\
& $\begin{array}{l}\text { Needles placed on Jiaji points T8-T12 bilaterally for } 30 \text { minutes once per day for } 3 \text { days. A post-treat- } \\
\text { ment follow-up was done }\end{array}$ \\
& $\begin{array}{l}\text { Needles } 40 \mathrm{~mm} \times 0.30 \text { mm inserted perpendicularly to } 25 \text { mm depth } \\
\text { Group 2: Dong Band Acuprime sham placebo needles were connected to the stimulator but with zero } \\
\text { frequency and current }\end{array}$ \\
\hline
\end{tabular}

Outcomes

Pain on NRS after 3 treatments and at 2 days post-treatment follow-up

\section{Notes}


Chen 2013 (Continued)

\section{Risk of bias}

\begin{tabular}{lll}
\hline Bias & Authors' judgement & Support for judgement \\
\hline $\begin{array}{l}\text { Random sequence genera- } \\
\text { tion (selection bias) }\end{array}$ & Low risk & Random number tables were used \\
\hline $\begin{array}{l}\text { Allocation concealment } \\
\text { (selection bias) }\end{array}$ & High risk & Allocation concealment was not reported \\
\hline $\begin{array}{l}\text { Blinding (performance } \\
\text { bias and detection bias) } \\
\text { All outcomes }\end{array}$ & High risk & Blinding was not reported \\
\hline $\begin{array}{l}\text { Incomplete outcome data } \\
\text { (attrition bias) } \\
\text { All outcomes }\end{array}$ & Low risk & Dropouts and withdrawals adequately described \\
\hline $\begin{array}{l}\text { Other bias } \\
\text { Sample size }\end{array}$ & Low risk & Nigh risk \\
\hline
\end{tabular}

\section{Dang 1998}

\section{Study characteristics}

\begin{tabular}{|c|c|}
\hline Methods & RCT using a block design with 3 pain groups, 2 intervention arms and 2 control groups \\
\hline Participants & $\begin{array}{l}48 \text { gastric cancer participants divided into } 3 \text { groups: 'mild', 'moderate' and 'severe' pain. Adults aged } \\
37-75.16 \text { healthy controls were also included }\end{array}$ \\
\hline \multirow[t]{4}{*}{ Interventions } & $\begin{array}{l}\text { Group 1: filiform needle group }(n=16): 7 \text { main points }(4-5 \text { each session }+2-4 \text { adjuvant points), for } 20 \\
\text { minutes. Grade I patients treated daily, grades } 2 \& 3 \text { treated } 2-3 \text { times daily. Each course lasted } 2 \text { weeks } \\
\text { with 2-3 days in between courses over a } 2 \text { month period }\end{array}$ \\
\hline & $\begin{array}{l}\text { Group 2: point injection group }(n=16) \text { : } 4 \text { main points } \times 2 \text { per week over } 2 \text { months. Injected with transfer } \\
\text { factor }\end{array}$ \\
\hline & $\begin{array}{l}\text { Group 3: Western medicine group }(n=16) \text { : analgesia was administered according to the WHO guide- } \\
\text { lines }\end{array}$ \\
\hline & Group 4: healthy controls $(n=16)$ : no intervention \\
\hline
\end{tabular}

Outcomes

Pain during the first 10 days and the final 10 days based on the Graded WHO criteria

Changes in leucine-enkephalin in plasma (PLEK)

Changes in CuZn-superoxide (CuZn-SOD) dismutase activity in whole blood

Patient-reported chemotherapy reactive symptoms (e.g. dizziness, vomiting)

\section{Notes}

\section{Risk of bias}

Bias Authors' judgement Support for judgement


Dang 1998 (Continued)
Random sequence genera- Low risk
Randomised block experimental design used but method of randomisation tion (selection bias) not described, and not stated whether this was carried out by blinded person- nel

\begin{tabular}{|c|c|c|}
\hline $\begin{array}{l}\text { Allocation concealment } \\
\text { (selection bias) }\end{array}$ & High risk & Allocation concealment was not stated \\
\hline Other bias & High risk & $\begin{array}{l}\text { Inappropriate control group of healthy participants } \\
\text { Poor reporting of methodology and intervention }\end{array}$ \\
\hline
\end{tabular}

Lu 2012

\section{Study characteristics}

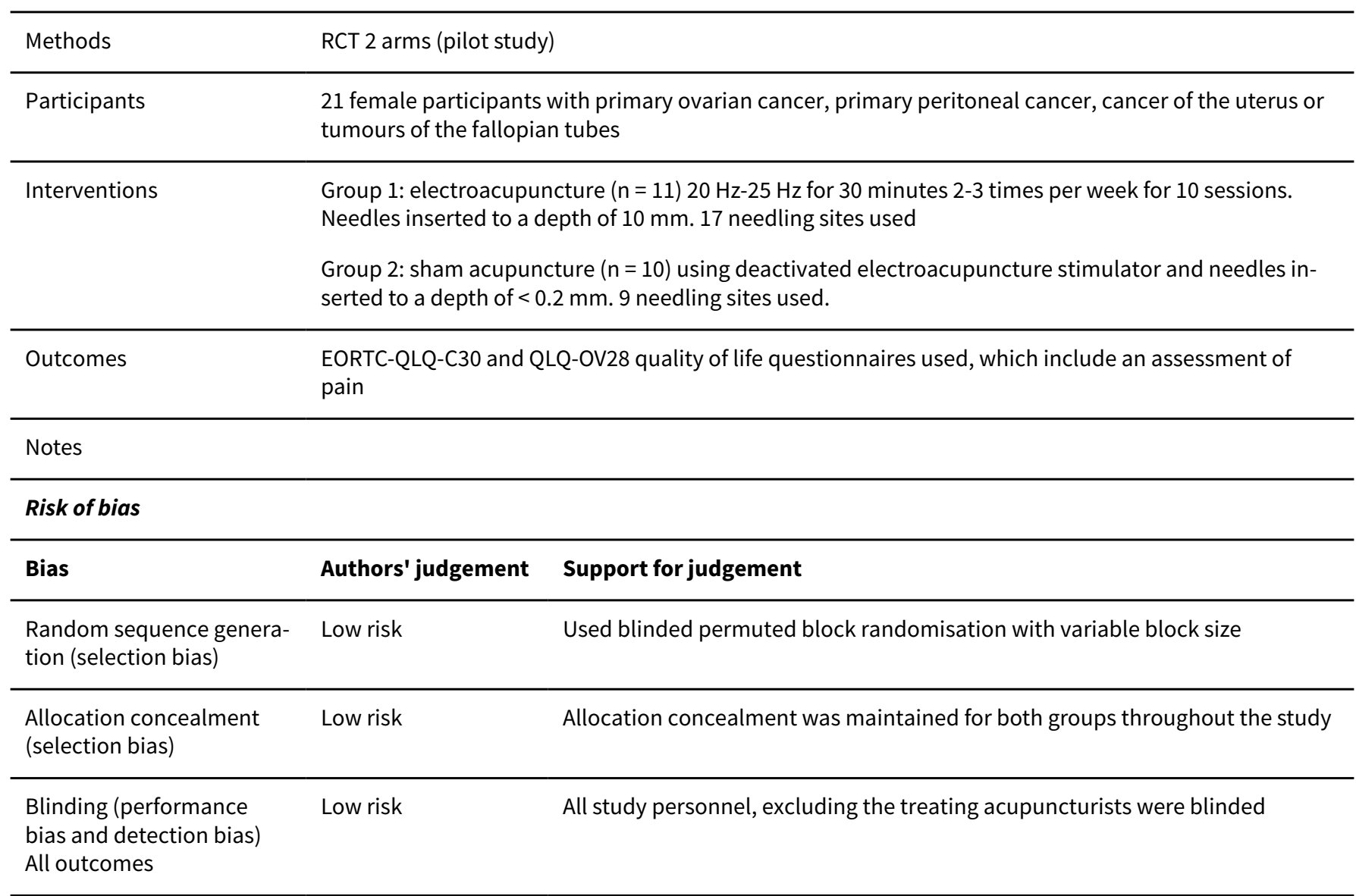




\section{Lu 2012 (Continued)}

$\begin{array}{ll}\begin{array}{l}\text { Incomplete outcome data } \\ \text { (attrition bias) }\end{array} & \begin{array}{l}\text { Withdrawals and dropouts were adequately reported. These were because of } \\ \text { disease progression }(n=4) \text { and the side-effects of chemotherapy }(n=1) . \text { One } \\ \text { All outcomes }\end{array} \\ \text { participant in the sham group was disqualified }\end{array}$

\begin{tabular}{lll}
\hline Other bias & Unclear risk & $\begin{array}{l}\text { There was no record of additional analgesic medication taken, or changes in } \\
\text { analgesic medication during the course of the study }\end{array}$ \\
\hline Sample size & High risk & 21 participants randomised to 2 groups
\end{tabular}

EORTC = European Organisation for Research and Treatment of Cancer

$\mathrm{RCT}=$ randomized controlled trial

NRS = numerical rating scale

VAS = visual analogue score

WHO $=$ World Health Organization

Characteristics of excluded studies [ordered by study ID]

\begin{tabular}{|c|c|}
\hline Study & Reason for exclusion \\
\hline Akhileswaran 2010 & Conference abstract with no traceable published paper \\
\hline Aung 1994 & Not an RCT of acupuncture for cancer pain \\
\hline Carr 2002 & Narrative review of evidence on acupuncture for cancer pain. No clinical data included \\
\hline Goudas 2001 & Narrative review of evidence on acupuncture for cancer pain. No clinical data included \\
\hline Guo 1995 & This contained clinical data on acupuncture for cancer pain but was not an RCT \\
\hline He 2013 & $\begin{array}{l}\text { Non-standard measures of pain used. Treatment group received transdermal fentanyl and acu- } \\
\text { point injections in addition to auricular acupuncture }\end{array}$ \\
\hline Hu 2011 & Not an RCT \\
\hline Liu 2010 & A strong analgesic injection was carried out at ST36 in the treatment group \\
\hline Meng 2002 & This is a discussion paper on the use of traditional Chinese medicine in oncology \\
\hline Minton 2007 & This is a letter within a journal and contained no clinical data \\
\hline Nguyen 2005 & This is a systematic review of acupuncture for cancer pain \\
\hline Poulain 1985 & $\begin{array}{l}\text { This study investigated pre and post-operative analgesia in cancer patients compared with } \\
\text { acupuncture analgesia }\end{array}$ \\
\hline Sima 2009 & Conference abstract only. No traceable published paper \\
\hline Wang 2010 & The intervention included injections of angelica \\
\hline Xia 1986 & Pain was not reported as an outcome measure in this study \\
\hline Yu 1992 & $\begin{array}{l}\text { This is a discussion paper on the use of traditional Chinese medicine to control cancer pain, and in- } \\
\text { cludes various traditional Chinese interventions. No clinical data were included }\end{array}$ \\
\hline Zhang 2006 & This was a study on the use of herbal treatments for cancer pain. No acupuncture was included \\
\hline
\end{tabular}


$\mathrm{RCT}=$ randomised controlled trial

\section{ADDITIONAL TABLES}

Table 1. Acupuncture for cancer pain in adults: summary of included studies

\begin{tabular}{|c|c|c|c|c|c|}
\hline Author (year) & Design & $\begin{array}{l}\text { Groups and interven- } \\
\text { tions }\end{array}$ & $\begin{array}{l}\text { Pain outcome } \\
\text { measures }\end{array}$ & $\begin{array}{l}\text { Secondary } \\
\text { outcomes }\end{array}$ & Pain results \\
\hline Alimi 2003 & $\begin{array}{l}\mathrm{RCT}, \mathrm{n}=90 \\
\text { single-blind } 3 \\
\text { groups }\end{array}$ & $\begin{array}{l}3 \text { groups: } \\
\text { - auricular acupunc- } \\
\text { ture, } \\
\text { - auricular acupunc- } \\
\text { ture at placebo } \\
\text { points, } \\
\text { - auricular seed at } \\
\text { placebo points) }\end{array}$ & $\begin{array}{l}\text { Pain intensity on } \\
\text { VAS at D30 and } \\
\text { D60 }\end{array}$ & $\begin{array}{l}\text { Average elec- } \\
\text { trical poten- } \\
\text { tial difference } \\
\text { at D30 and } \\
\text { D60 }\end{array}$ & $\begin{array}{l}\text { Pain intensity on VAS significantly } \\
\text { decreased in acupuncture group } \\
\text { compared with placebo at both } \\
\text { D30 and D60 }\end{array}$ \\
\hline
\end{tabular}

\begin{tabular}{llll}
\hline Chen 2008 & RCT $n=66$, & 3 groups: 'mild', 'mod- & Analgesic effect: \\
& $\begin{array}{l}\text { 3 groups, } 2 \\
\text { subgroups for }\end{array}$ & $\begin{array}{l}\text { erate' and 'severe' } \\
\text { pain, each group ran- }\end{array}$ & - complete re- \\
each group & $\begin{array}{l}\text { domly subdivided into } \\
\text { 2 subgroups: acupunc- }\end{array}$ & - avef \\
& $\begin{array}{ll}\text { ture group and med- } \\
\text { ication group }\end{array}$ & - partial relief \\
& & - no relief
\end{tabular}

None reported General effectiveness (\%) in acupuncture group: mild pain = $100 \%$; moderate pain $=94.4 \%$; severe pain $=91.7 \%$

In medication group: mild pain = $75 \%$; moderate pain $=89.5 \%$; severe pain $=88.9 \%$

Groups compared for general effectiveness: acupuncture $=$ $94.1 \%$; medication $=87.5 \%$

$\begin{array}{llll}\text { Chen } 2013 \quad \begin{array}{l}\text { RCT } n=60,2 \\ \text { groups }\end{array} & \begin{array}{l}\text { 2 groups random- } \\ \text { ly assigned to elec- } \\ \text { troacupuncture or a } \\ \text { placebo control }\end{array} & \begin{array}{l}\text { NRS at baseline } \\ \text { and after } 3 \text { days } \\ \text { of treatment }\end{array} & \begin{array}{l}\text { None reported } \\ \text { The difference between groups in } \\ \text { pain scores was statistically sig- } \\ \text { nificant after } 3 \text { treatments com- } \\ \text { pared with baseline }(P \text { value }< \\ 0.001) \text { and also at } 3 \text { day follow-up } \\ \text { (P value }<0.001)\end{array}\end{array}$

\begin{tabular}{|c|c|c|c|c|c|}
\hline Dang 1998 & $\begin{array}{l}\mathrm{RCT}, \mathrm{n}=48,4 \\
\text { groups }\end{array}$ & $\begin{array}{l}3 \text { pain groups ran- } \\
\text { domly divided into } 3 \\
\text { groups: } \\
\text { - filiform needle (FN) } \\
\text { - point injection (PI) } \\
\text { and } \\
\text { - Western medicine } \\
\text { (WM) } \\
\text { There was also } 1 \text { con- } \\
\text { trol group of healthy } \\
\text { subjects }\end{array}$ & $\begin{array}{l}\text { Treatment effec- } \\
\text { tiveness \% score } \\
\text { based on } 3 \text { cate- } \\
\text { gories: } \\
\text { 'markedly effec- } \\
\text { tive' } \\
\text { 'improved' } \\
\text { 'ineffective'. } \\
\text { Categories in- } \\
\text { cluded pain, } \\
\text { vigour, sleep and } \\
\text { appetite }\end{array}$ & $\begin{array}{l}\text { PLEK concen- } \\
\text { tration } \\
\text { Quality of life } \\
\text { Chemother- } \\
\text { apeutic reac- } \\
\text { tion } \\
\text { E-RFR (\%) } \\
\text { Leukocyte } \\
\text { count }\end{array}$ & $\begin{array}{l}\text { After } 2 \text { months total effective } \\
\text { rates of analgesia were around } \\
81 \% \text { for FN, PI and WM groups } \\
\text { and the markedly effective scores } \\
\text { were FN } 48.8 \%, \mathrm{PI} 51.9 \% \text { and WM } \\
33.8 \%\end{array}$ \\
\hline Lu 2012 & $\begin{array}{l}\text { RCT (pilot) } \\
n=21\end{array}$ & $\begin{array}{l}2 \text { groups randomly } \\
\text { divided into an elec- } \\
\text { troacupuncture group } \\
\text { and a sham elec- } \\
\text { troacupuncture group }\end{array}$ & $\begin{array}{l}\text { EORTC quali- } \\
\text { ty of life ques- } \\
\text { tionnaires giving } \\
\text { scores for pain }\end{array}$ & $\begin{array}{l}\text { This was a re- } \\
\text { port of a sec- } \\
\text { ondary out- } \\
\text { come (quali- }\end{array}$ & $\begin{array}{l}\text { There was no significant differ- } \\
\text { ence in pain scores between } \\
\text { groups although both groups } \\
\text { showed a reduction in pain }\end{array}$ \\
\hline
\end{tabular}


Table 1. Acupuncture for cancer pain in adults: summary of included studies (Continued)

$\mathrm{D} 30=$ day 30

D60 $=$ day 60

$\mathrm{E}-\mathrm{RFR}=$

EORTC $=$

NRS = numerical rating scale

PLEK =

$\mathrm{RCT}=$ randomised controlled trial

VAS = visual analogue scale

\section{A P P E N D I CES}

\section{Appendix 1. Original review search strategies}

\section{MEDLINE}

2. 1. exp Acupuncture Therapy/ (11796)2. exp Medicine, East Asian Traditional/ (9312)3. Acupuncture/ (860)4. (acupuncture or acupressure or acupoint* or electroacupuncture or electro-acupuncture or meridian* or moxibust* or "traditional chinese medicine" or "traditional oriental medicine").mp. [mp=title, original title, abstract, name of substance word, subject heading word] (19418)5. 4 or 1 or 3 or 2 (26132)6. exp Neoplasms/ (2075388)7. (neoplasm or cancer* or carcino* or malignan* or tumor* or tumour ${ }^{\star}$ ).mp. [mp=title, original title, abstract, name of substance word, subject heading word] (2221292)8. or/6-7 (2483290)9. exp Pain/ (246185)10. pain*.mp. [mp=title, original title, abstract, name of substance word, subject heading word] (376859)11. Analgesia/ (11230)12. (analges* or nocicept ${ }^{\star}$ or $^{*}$ neuropath*).mp. [mp=title, original title, abstract, name of substance word, subject heading word] (189913)13. or/9-12 (559785)14. 13 and 8 and 5 (275)15. randomized controlled trial.pt. (280165)16. controlled clinical trial.pt. (80498)17. randomized.ab. (189021)18. placebo.ab. (115356)19. drug therapy.fs. (1346163)20. randomly.ab. (136940)21. trial.ab. (195831)22. groups.ab. (935356)23. or/15-22 (2465926)24. exp animals/ not humans.sh. (3448923)25. 23 not 24 (2089714)26. 25 and 14 (88)28. 2009 ${ }^{\star \star \star \star}$.ed. (506278)29. 26 and 27 (7)

Cochrane Highly Sensitive Search Strategy for identifying randomized trials in MEDLINE: sensitivity-maximizing version (2008 revision); OVID format

1. randomized controlled trial.pt.

2. controlled clinical trial.pt.

3. randomized.ab.

4. placebo.ab.

5. drug therapy.fs.

6. randomly.ab.

7. trial.ab.

8. groups.ab.

9. 1 or 2 or 3 or 4 or 5 or 6 or 7 or 8

10.Animals.sh. not (humans.sh. and animals.sh.)

11.9 not 10

Total number of records found: 63

\section{CENTRAL}

1. Cancer near pain

2. Bone Pain

3. Metasta\$

4. \#1 or \#2 or \#3

5. Acupuncture

6. Complementary therapy [ti,ab,kw]

7. \#5 and \#6

8. \#4 and \#7 
Total number of records found: 51

\section{AMED}

1. (acupuncture or acupressure or acupoint ${ }^{\star}$ or electroacupuncture or electro-acupuncture or meridian* or moxibust* or "traditional chinese medicine" or "traditional oriental medicine").mp. [mp=abstract, heading words, title] (8895)

2. (neoplasm or cancer $^{\star}$ or carcino* or malignan ${ }^{\star}$ or tumor ${ }^{\star}$ or tumour $\left.{ }^{\star}\right) \cdot \mathrm{mp}$. [mp=abstract, heading words, title] (12845)

3. pain*.mp. [mp=abstract, heading words, title] (21140)

4. (analges ${ }^{\star}$ or nocicept ${ }^{\star}$ or neuropath $\left.{ }^{\star}\right) \cdot \mathrm{mp}$. [mp=abstract, heading words, title] (4063)

5. 4 or $3(22808)$

6. 1 and 2 and $5(71)$

7. exp randomized controlled trials/ (1350)

8. exp double blind method/ (388)

9. exp random allocation/ (288)

10. (random\$ or control\$ or placebo $\$$ or factorial).mp. [mp=abstract, heading words, title] (27645)

11.(double adj blind).mp. [mp=abstract, heading words, title] (1296)

12.(single adj blind).mp. [mp=abstract, heading words, title] (305)

13.exp comparative study/ (4134)

14.or/7-13 (30652)

15.6 and 14 (27)

16.from 15 keep 1-27 (27)

\section{EMBASE}

1. acupuncture/ or acupuncture analgesia/ or electroacupuncture/ or acupressure/ (13166)

2. exp ACUPUNCTURE THERAPY/ (13179)

3. chinese medicine/ or oriental medicine/ (8536)

4. (acupuncture or acupressure or acupoint* or electroacupuncture or electro-acupuncture or meridian* or moxibust* or "traditional chinese medicine" or "traditional oriental medicine").mp. [mp=title, abstract, subject headings, heading word, drug trade name, original title, device manufacturer, drug manufacturer name] (18853)

5. 2 or 4 or 1 or $3(23706)$

6. exp Neoplasms/ (1481026)

7. (neoplasm* or cancer ${ }^{\star}$ or carcino* or malignan* or tumor ${ }^{\star}$ or tumour $\left.{ }^{\star}\right) . m p$. [mp=title, abstract, subject headings, heading word, drug trade name, original title, device manufacturer, drug manufacturer name] (1605212)

8. or/6-7 (1845304)

9. exp Pain/ (375235)

10. pain ${ }^{\star} . \mathrm{mp}$. [mp=title, abstract, subject headings, heading word, drug trade name, original title, device manufacturer, drug manufacturer name] (371531)

11.Analgesia/ (43678)

12. (analges* or nocicept ${ }^{\star}$ or neuropath $\left.{ }^{\star}\right) . \mathrm{mp}$. [mp=title, abstract, subject headings, heading word, drug trade name, original title, device manufacturer, drug manufacturer name] (221904)

13.or/9-12 (617984)

14.8 and 13 and 5 (615)

15.random*.ti,ab. (397881)

16. factorial ${ }^{\star} . t i$, ab. (8307)

17. (crossover ${ }^{\star}$ or cross over ${ }^{\star}$ or cross-over $\left.{ }^{\star}\right)$.ti,ab. (39692)

18.placebo*.ti,ab. (110792)

19. $\left(\right.$ doubl$^{\star}$ adj blind $\left.{ }^{\star}\right) \cdot$ ti,ab. (85277)

20.(singl* adj blind $\left.{ }^{\star}\right) . t i, a b . ~(7523)$

21.assign ${ }^{\star}$.ti,ab. (109581)

22.allocat ${ }^{\star}$.ti,ab. (34657)

23.volunteer*.ti,ab. (99728)

24.CROSSOVER PROCEDURE.sh. (21298)

25.DOUBLE-BLIND PROCEDURE.sh. (72449)

26.RANDOMIZED CONTROLLED TRIAL.sh. (168923) 
27.SINGLE BLIND PROCEDURE.sh. (8167)

28.or/15-27 (665787)

29.ANIMAL/ or NONHUMAN/ or ANIMAL EXPERIMENT/ (3460363)

30. HUMAN/ (6490253)

31.29 and 30 (541210)

32.29 not 31 (2919153)

33.28 not 32 (579835)

34.33 and 14 (107)

35.from 34 keep 1-107 (107)

Total number of records found: 77

\section{Psycinfo}

1. (acupuncture or acupressure or acupoint* or electroacupuncture or electro-acupuncture or meridian* or moxibust* or "traditional chinese medicine" or "traditional oriental medicine").mp. [mp=title, abstract, heading word, table of contents, key concepts] (1679)

2. (neoplasm* or cancer ${ }^{\star}$ or carcino* or malignan ${ }^{\star}$ or tumor $^{\star}$ or tumour $\left.{ }^{\star}\right)$.mp. [mp=title, abstract, heading word, table of contents, key concepts] (28978)

3. pain ${ }^{\star} . \mathrm{mp}$. [mp=title, abstract, heading word, table of contents, key concepts] (50211)

4. (analges ${ }^{\star}$ or nocicept ${ }^{\star}$ or neuropath*).mp. [mp=title, abstract, heading word, table of contents, key concepts] (22783)

5. 4 or $3(63662)$

6. 1 and 2 and $5(21)$

7. randomized.ab. (18521)

8. placebo.ab. (21105)

9. randomly.ab. (33558)

10.trial.ab. (36218)

11.groups.ab. (234910)

12.or/7-11 (304624)

13.6 and $12(8)$

14.from 13 keep 1-8 (8)

Total number of records found: 3

\section{SportDiscus (EBSCO)}

1. S1 and S2 and S3 (9)

2. pain $^{\star}$ or analges ${ }^{\star}$ or nocicept ${ }^{\star}$ or neuropath ${ }^{\star}$ (30909)

3. neoplasm ${ }^{\star}$ or cancer ${ }^{\star}$ or carcino ${ }^{\star}$ or malignan ${ }^{\star}$ or tumor $^{\star}$ or tumour ${ }^{\star}(13267)$

4. acupuncture or acupressure or acupoint ${ }^{\star}$ or electroacupuncture or electro-acupuncture or meridian* or moxibust $^{\star}$ (1062)

Total number of records found: 9

\section{Appendix 2. 2014 search strategies}

\section{CENTRAL (CRSO)}

MESH DESCRIPTOR Acupuncture Therapy EXPLODE ALL TREES

MESH DESCRIPTOR Medicine, East Asian Traditional EXPLODE ALL TREES

MESH DESCRIPTOR Acupuncture

((acupuncture or acupressure or acupoint ${ }^{\star}$ or electroacupuncture or electro-acupuncture or meridian* or moxibust* or "traditional chinese medicine" or "traditional oriental medicine")):TI,AB,KY

\#1 OR \#2 OR \#3 OR \#4

MESH DESCRIPTOR Neoplasms EXPLODE ALL TREES

(neoplasm or cancer $^{\star}$ or carcino* or malignan ${ }^{\star}$ or tumor ${ }^{\star}$ or tumour ${ }^{\star}$ ) 
\#6 OR \#7

MESH DESCRIPTOR Pain EXPLODE ALL TREES

pain*:TI,AB,KY

MESH DESCRIPTOR Analgesia

((analges ${ }^{\star}$ or nocicept ${ }^{\star}$ or neuropath $\left.\left.{ }^{\star}\right)\right): \mathrm{TI}, \mathrm{AB}, \mathrm{KY}$

\#9 OR \#10 OR \#11 OR \#12

\#5 AND \#8 AND \#13

2010 TO 2014:YR

\#14 AND \#15

MEDLINE (OVID)

1. exp Acupuncture Therapy/

2. exp Medicine, East Asian Traditional/

3. Acupuncture/

4. (acupuncture or acupressure or acupoint ${ }^{\star}$ or electroacupuncture or electro-acupuncture or meridian* or moxibust* or "traditional chinese medicine" or "traditional oriental medicine").mp. [mp=title, abstract, original title, name of substance word, subject heading word, keyword heading word, protocol supplementary concept word, rare disease supplementary concept word, unique identifier]

5. or/1-4

6. exp Neoplasms/

7. (neoplasm* or cancer* or carcino* or malignan* or tumor* or tumour $\left.{ }^{\star}\right) . m p$. [mp=title, abstract, original title, name of substance word, subject heading word, keyword heading word, protocol supplementary concept word, rare disease supplementary concept word, unique identifier]

8.6 or 7

9. exp Pain/

10. pain*.mp.

11. Analgesia/

12. (analges ${ }^{\star}$ or nocicept ${ }^{\star}$ or neuropath*).mp. [mp=title, abstract, original title, name of substance word, subject heading word, keyword heading word, protocol supplementary concept word, rare disease supplementary concept word, unique identifier]

13. or/9-12

14. randomized controlled trial.pt.

15. controlled clinical trial.pt.

16. randomized.ab.

17. placebo.ab.

18. drug therapy.fs.

19. randomly.ab.

20. trial.ab.

21. groups.ab.

22. 14 or 15 or 16 or 17 or 18 or 19 or 20 or 21

Acupuncture for cancer pain in adults (Review) 
23. exp animals/ not humans.sh.

\section{22 not 23}

\section{5 and 8 and 13 and 24}

\section{EMBASE (OVID)}

1. acupuncture/ or acupuncture analgesia/ or electroacupuncture/ or acupressure/

\section{2. $\exp$ ACUPUNCTURE THERAPY/}

3. chinese medicine/ or oriental medicine/

4. (acupuncture or acupressure or acupoint ${ }^{\star}$ or electroacupuncture or electro-acupuncture or meridian ${ }^{\star}$ or moxibust ${ }^{\star}$ or "traditional chinese medicine" or "traditional oriental medicine").mp. [mp=title, abstract, subject headings, heading word, drug trade name, original title, device manufacturer, drug manufacturer, device trade name, keyword]

5. or/1-4

6. exp Neoplasms/

7. (neoplasm ${ }^{\star}$ or cancer ${ }^{\star}$ or carcino* or malignan* or tumor ${ }^{\star}$ or tumour $\left.{ }^{\star}\right) . \mathrm{mp}$. [mp=title, abstract, subject headings, heading word, drug trade name, original title, device manufacturer, drug manufacturer, device trade name, keyword]

\section{6 or 7}

9. exp Pain/

10. pain*.mp.

11. Analgesia/

12. (analges ${ }^{\star}$ or nocicept ${ }^{\star}$ or neuropath*).mp. [mp=title, abstract, subject headings, heading word, drug trade name, original title, device manufacturer, drug manufacturer, device trade name, keyword]

13. or/9-12

14. random\$.tw.

15. factorial\$.tw.

16. crossover\$.tw.

17. cross over\$.tw.

18. cross-over\$.tw.

19. placebo\$.tw.

20. (doubl\$ adj blind\$).tw.

21. (singl\$ adj blind\$).tw.

22. assign\$.tw.

23. allocat\$.tw.

24. volunteer\$.tw.

25. Crossover Procedure/

26. double-blind procedure.tw.

27. Randomized Controlled Trial/

28. Single Blind Procedure/

29. or/14-28

Acupuncture for cancer pain in adults (Review) 
30. (animal/ or nonhuman/) not human/

31. $29 \operatorname{not} 30$

32.5 and 8 and 13 and 31

\section{PsycINFO (OVID)}

\section{1. exp Neoplasms/}

2. (neoplasm ${ }^{\star}$ or cancer ${ }^{\star}$ or carcino* or malignan ${ }^{\star}$ or tumor ${ }^{\star}$ or tumour $\left.{ }^{\star}\right) . m p$. [mp=title, abstract, heading word, table of contents, key concepts, original title, tests \& measures]

3. 1 or 2

4. exp Pain/

5. pain $^{\star} . m p$

6. Analgesia/

7. (analges ${ }^{\star}$ or nocicept ${ }^{\star}$ or neuropath $\left.{ }^{\star}\right) . \mathrm{mp}$. [mp=title, abstract, heading word, table of contents, key concepts, original title, tests \& measures]

8. or/4-7

9. (acupuncture or acupressure or acupoint ${ }^{\star}$ or electroacupuncture or electro-acupuncture or meridian* or moxibust* or "traditional chinese medicine" or "traditional oriental medicine").mp. [mp=title, abstract, heading word, table of contents, key concepts, original title, tests \& measures]

10. acupuncture/

11.9 or 10

12. clinical trials/

13. (randomis ${ }^{\star}$ or randomiz*).tw.

14. (random\$ adj3 (allocat\$ or assign\$)).tw.

15. ((clinic\$ or control\$) adj trial\$).tw.

16. ((singl\$ or doubl\$ or trebl\$ or tripl\$) adj3 (blind\$ or mask\$)).tw.

17. (crossover\$ or "cross over\$").tw.

18. random sampling/

19. Experiment Controls/

20. Placebo/

21. placebo\$.tw.

22. exp program evaluation/

23. treatment effectiveness evaluation/

24. ((effectiveness or evaluat\$) adj3 (stud\$ or research\$)).tw.

25. or $/ 12-24$

26. 3 and 8 and 11 and 25

\section{AMED (OVID)}

1. acupuncture/

2. Traditional medicine chinese/

Acupuncture for cancer pain in adults (Review) 
3. Acupuncture therapy/

4. (acupuncture or acupressure or acupoint* or electroacupuncture or electro-acupuncture or meridian* or moxibust* or "traditional chinese medicine" or "traditional oriental medicine").mp. [mp=abstract, heading words, title]

5. or/1-4

6. exp neoplasms/

7. (neoplasm ${ }^{\star}$ or cancer ${ }^{\star}$ or carcino* or malignan ${ }^{\star}$ or tumor ${ }^{\star}$ or tumour $\left.{ }^{\star}\right) . m p$. [mp=abstract, heading words, title]

8. 6 or 7

9. exp pain/

10. pain*.mp.

11. Analgesia/

12. (analges ${ }^{\star}$ or nocicept ${ }^{\star}$ or neuropath $\left.{ }^{\star}\right) \cdot \mathrm{mp}$. [mp=abstract, heading words, title]

13. or/9-12

14.5 and 8 and 13

15. exp randomized controlled trials/

16. exp double blind method/

17. exp random allocation/

18. (random\$ or control\$ or placebo $\$$ or factorial).mp.

19. (double adj blind).mp.

20. (single adj blind).mp.

21. exp comparative study/

22. or $/ 15-21$

23. 14 and 22

\section{SportDiscus (EBSCO)}

(acupuncture or acupressure or acupoint ${ }^{\star}$ or electroacupuncture or electro-acupuncture or meridian* or moxibust ${ }^{\star}$ ) AND ( neoplasm or $^{\star}$ cancer $^{\star}$ or carcino* $^{\star}$ or malignan ${ }^{\star}$ or tumor ${ }^{\star}$ or tumour ${ }^{\star}$ ) AND ( pain* or analges ${ }^{\star}$ or nocicept $^{\star}$ or neuropath* $)$

\section{WHAT'S NEW}

\begin{tabular}{lll}
\hline Date & Event & Description \\
\hline 25 January 2021 & Review declared as stable & See Published notes. \\
\hline
\end{tabular}

\section{H I S T ORY}

Protocol first published: Issue 2, 2009

Review first published: Issue 1, 2011 


\begin{tabular}{lll}
\hline Date & Event & Description \\
\hline 9 July 2018 & Review declared as stable & See Published notes \\
\hline 4 November 2015 & Amended & Minor typos corrected. \\
\hline 16 October 2015 & Review declared as stable & This review will be assessed for updating in 2018. \\
\hline 31 August 2015 & New search has been performed & $\begin{array}{l}\text { New search completed for update on 31 July 2015. This review } \\
\text { has been updated to include the results of a new search, but the } \\
\text { conclusions remain the same. }\end{array}$ \\
\hline 9 April 2015 & New citation required but conclusions & $\begin{array}{l}\text { Two new studies were identified for inclusion in the review but } \\
\text { the evidence did not alter the conclusions due to the small size } \\
\text { of the studies and inconclusive findings. }\end{array}$ \\
\hline 25 April 2012 & Amended & $\begin{array}{l}\text { A correction was made by moving the 'Summary of included } \\
\text { studies' from the 'Summary of findings' table section to the 'Ad- } \\
\text { ditional tables' section in the review. }\end{array}$
\end{tabular}

\section{CONTRIBUTIONS OFAUTHORS}

Writing protocol: $\mathrm{CP}, \mathrm{AM}-\mathrm{B}, \mathrm{MJ}, \mathrm{OT}$.

Writing full review: $\mathrm{CP}, \mathrm{OT}, \mathrm{MJ}$.

Search databases: CP, OT.

Study selection: CP, OT, MJ.

Assessment of methodological quality: $\mathrm{CP}, \mathrm{OT}, \mathrm{MJ}$.

Data extraction: CP, OT, MJ.

Statistical analysis: CP, OT.

Review update: CP, OT, MJ

\section{DECLARATIONS OF INTEREST}

CP has no relevant conflicts of interest to declare.

OT has no relevant conflicts of interest to declare.

AM-B has no relevant conflicts of interest to declare.

MJ has no relevant conflicts of interest to declare.

\section{SOURCES OF SUPPORT}

\section{Internal sources}

- Leeds Beckett University, UK

Academic support for the project.

\section{External sources}

- No sources of support supplied 


\section{DIFFERENCES BETWEEN PROTOCOL AND REVIEW}

We had planned to do a subgroup analysis on cancer-induced bone pain, but this was not possible because this condition was not specifically mentioned in any of the papers reviewed. Heterogeneity prevented pooling of data and meta-analysis and forest plots were not included because these would have only included single-study analyses.

\section{NOTES}

\section{Assessed for updating in 2018}

A restricted search in July 2018 did not identify any potentially relevant studies likely to change the conclusions. Therefore, this review has now been stabilised following discussion with the authors and editors. The review will be re-assessed for updating in two years. If appropriate, we will update the review before this date if new evidence likely to change the conclusions is published, or if standards change substantially which necessitates major revisions.

\section{Assessed for updating in $\mathbf{2 0 2 0}$}

We performed a restricted updated search in November 2020. We are not aware of any potentially relevant studies likely to change the conclusions. Therefore, this review has now been stabilised following discussion with the authors and editors. The review will be reassessed for updating in two years. If appropriate, we will update the review before this date if new evidence likely to change the conclusions is published, or if standards change substantially which necessitate major revisions.

\section{INDEX TERMS}

\section{Medical Subject Headings (MeSH)}

Acupuncture Therapy [ ${ }^{*}$ methods]; Acupuncture, Ear [methods]; Neoplasms [ ${ }^{*}$ complications]; Pain [etiology]; Pain Management [ ${ }^{\star}$ methods]; Pain Measurement; Randomized Controlled Trials as Topic

\section{MeSH check words}

Adult; Humans 